Portland State University

PDXScholar

Summer 11-6-2014

\title{
The Stories We Tell: A Qualitative Inquiry to Multiracial Family Storytelling
}

Mariko 0. Thomas

Portland State University

Follow this and additional works at: https://pdxscholar.library.pdx.edu/open_access_etds

Part of the Gender, Race, Sexuality, and Ethnicity in Communication Commons Let us know how access to this document benefits you.

Recommended Citation

Thomas, Mariko O., "The Stories We Tell: A Qualitative Inquiry to Multiracial Family Storytelling" (2014). Dissertations and Theses. Paper 2148.

https://doi.org/10.15760/etd.2146

This Thesis is brought to you for free and open access. It has been accepted for inclusion in Dissertations and Theses by an authorized administrator of PDXScholar. Please contact us if we can make this document more accessible: pdxscholar@pdx.edu. 
The Stories We Tell:

A Qualitative Inquiry to Multiracial Family Storytelling

by

Mariko O. Thomas

A thesis submitted in partial fulfillment of the requirements for the degree of

Master of Science

in

Communication

Thesis Committee:

David Ritchie, Chair

Priya Kapoor

Jeffrey Robinson

Portland State University

2014 
(C) 2014 Mariko O. Thomas

The Stories We Tell: A Qualitative Inquiry to Multiracial Family Storytelling by Mariko O. Thomas is licensed under the Creative Commons AttributionNoDerivatives 4.0 International License. To view a copy of this license, visit http://creativecommons.org/licenses/by-nd/4.0/. (c) $(7)$ 


\begin{abstract}
A narrative inheritance is comprised of the stories told by family members that are received by a younger generation and used to help construct identity. According to the communication theory of identity, identity is formed through communication.

Additionally, the storied resource perspective looks at narratives as a major method of creating and maintaining identity. This study looks at the kinds of narrative inheritance concerning race that people in multiracial families receive and possible ways it affects racial identity formation. Findings from 12 semi-structured interviews indicate that narratives of racism, cultural pride, and hardship are prevalent in multiracial families. Additionally, findings show that varying family structures may affect the transference of racial narratives between generations, which can in turn affect how multiracial children choose to identify themselves racially.
\end{abstract}

Keywords: communication theory of identity, narrative inheritance, multiracial identity, family storytelling 


\section{Acknowledgments}

I would like to thank my wonderful committee for their support and advice through all the metamorphoses this project has gone through. Dr. Ritchie, your enthusiasm for new ideas is inspiring and Dr. Robinson, the clarity and meticulousness of your instruction was always helpful. Dr. Kapoor, I appreciate the amount of heart you approach research with, and was greatly aided by your sensitivity to race and narratives throughout this project. Ben Smith, you are a formatting whizz, thanks for the endless supply of tea and support. Thank you also to the Portland State University communication department for the funding that made this project possible.

I would also like to thank the participants who took the time to share their stories, as it was such a privilege to be on the receiving end of the narratives that helped shape people's lives. Within that, I would like to thank the enormous and ever-vibrant Thomas family, as their narratives got me started on this path of research and continue to play a part in both my life and my work. 
Table of Contents

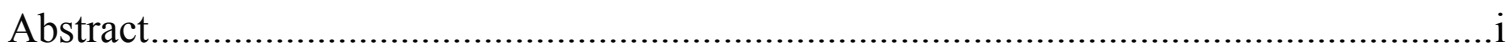

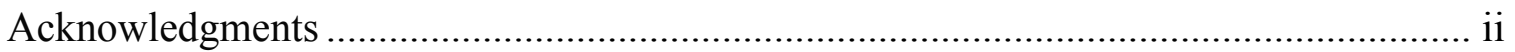

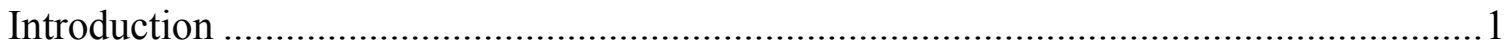

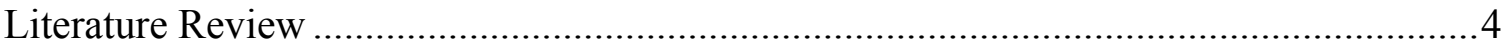

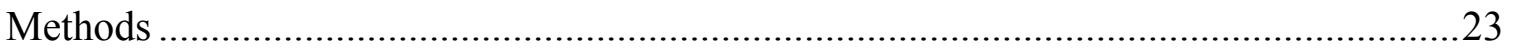

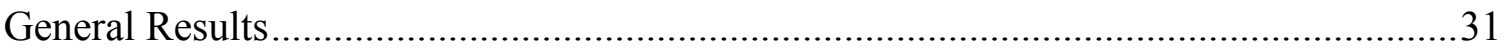

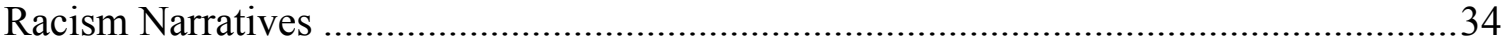

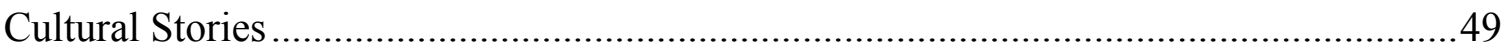

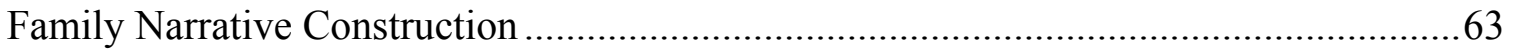

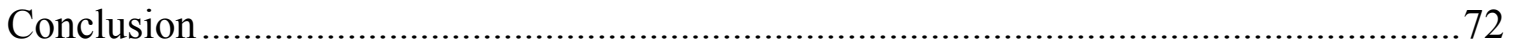

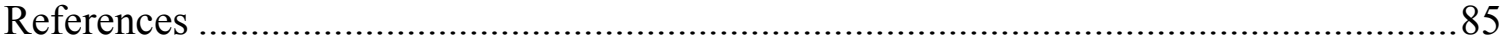

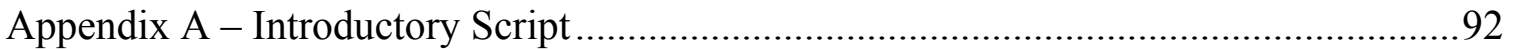

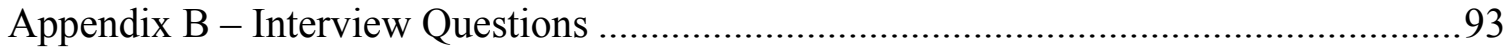

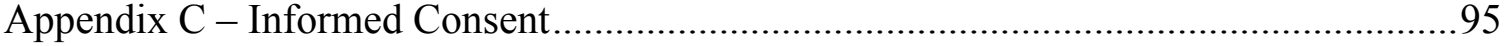

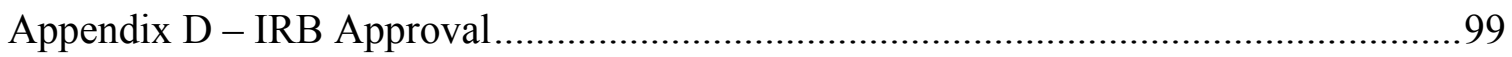


Introduction

"Our racial identity is not in our genes, but in the world in which we live and in the stories we choose to construct and are able to maintain" (Baylis, 2003, p.149).

Arriving at racial identity can often prove to be one of the most difficult developmental processes a multiracial child can embark upon. Needing to temper, understand, assimilate, and defend more than one race on a regular basis can be a complicated matter, and choosing how to define and perform those racial identities only adds to the difficulty. Categorization based on race is often implied as a societal demand (Hitlin, Brown, \& Elder, 2006), and many people are uncomfortable when left uncertain of the racial heritage of the person they are interacting with, unsure of how to culturally relate to ambiguous but obvious racial difference. As written about by Root (1992), Brown (2001), Dacosta (2007) and Williams (2007), multiracial people face the oftenharrowing inquiry of "what are you?"

This is rarely an easy question to answer for multiracial people due to the complicated interplay between their personal identities, their parents' identities, and their physical appearance. Additionally, those inquiring are often looking for a direct answer to affirm their perception of visible appearance. Answers that fail to fulfill the inquirer's initial perception of ethnicity or race are often met with challenges, or more invasive questions about lineage of parents. However, these questions often fail to get at the root of the matter, and instead tend to only look at assumptions of genetics. As Baylis (2003) beautifully remarked, racial identity cannot be reduced to a simple question of genetics, 
as it exists in the stories people construct, maintain, and hold onto, as well as in the world around them.

Omi and Winant's (1994) seminal work laid the groundwork for race to be described and conceptualized as a socially learned feature in society, and something that is a complicated and lengthy construction of lived experiences and social interactions. In many families, interactions among members are one of the first points of social contact, and the starting point for construction of racial identity. Furthermore, in the case of multiracial children and the relatively high amount of social contestation and questioning they are likely to face (Dacosta, 2007), family communication can be a preliminary sense-making device for understanding mixed race identity, and ethnic and racial socialization can begin at a very young age (Lesane-Brown, Brown, Tanner-Smith, \& Bruce, 2010).

This socialization is performed for various reasons and highlights various priorities in different families and different cultures. Thomas, Speight \& Witherspoon (2010) found that racial socialization in African-American families is a method of defense and preparation for possible acts of racism that children might encounter throughout their lives. Joseph, Watson, Wang, Case \& Hunter (2013) found that in some second-generation Haitian families, messages of cultural socialization, mainstream socialization, and preparation for racially biased societal messages were given to children from their families. While some research has been conducted on what families talk about with issues of race and identity, there has been very little produced on precisely how this is completed, and even less that addresses the process of family storytelling as a plausible 
method of communicating and developing the intricate familial and personal racial identities that are often present in mixed race families.

Langellier and Peterson (2004) argue that storytelling is an implemental process through which families can express both their group membership and their connection to one another. Storytelling, or the process of sharing narratives, works as a vehicle for passing narratives both down through generations as well as horizontally in a family (Langellier \& Peterson, 2004). Ballard \& Ballard (2011), Tyler (2005) and Goodall (2005) use the term 'narrative inheritance' to describe the stories that are passed down through generations in families, and implemental in the building of familial and personal identities, racially and otherwise. The purpose of this study is to qualitatively gain more knowledge and contribute to an academic conversation about the narrative inheritance that multiracial individuals may receive from their families, the processes of how these narratives are constructed and shared, and the possible important role they might play in helping multiracial individuals determine their racial identity. Additionally, this paper aims to elucidate some of the inner conflicts and struggles of growing up multiracial, and inquire as to how narrative inheritance might stifle, clarify, encourage, or otherwise intersect with development of multi-racial identity. 
Literature Review

\section{On multiracial identification}

The year 1967 was a landmark for political acceptance of mixed race families in the United States. With the civil rights movement in the background, the last laws against interracial marriage and miscegenation were ruled unconstitutional in Loving $v$. Virginia (Root, 1992). The newly established legality of mixed race marriages laid groundwork for the conversation to commence about mixed race America in several new social spheres. However, even with political recognition of mixed race families, the census system in place still forced children from interracial marriages to pick single races with which to identify, in compliance with a 'mark one' racial categorization system. Available choices were White, Black, Hispanic, Japanese, Chinese Filipino, Korean, Vietnamese, American Indian, Asian Indian, Hawaiian, Guamanian, Somoan, Eskimo, Aleut, or 'other' (Dacosta, 2007). For those who felt their personal identity bridged more than one race, there was little to do but mark 'other', a label vague and dehumanizing by most accounts (Said, 1978). Gordon (1997) remarked that historically, racial identification meant either Black or White, but any mixture placed individuals in an institutional state of 'racelessness', resulting in a mixed-race population that was somewhat ignored and largely unaccounted for.

It was not until 1997 that race categorization in the census system was truly restructured. 1997 is frequently cited as the most relevant institutional turning point for addressing the mixed race population of U.S. America, as it produced the first census where respondents had the option to "mark one or more" racial categories (Perez \& 
Hirschman, 2009). Not only did this mark an overdue movement forward in public recognition of multiracial individuals, but it was also a symbolic encouragement for people with complicated racial identities to assert more than one race if they wanted to. Individuals were no longer forced to either just choose part of themselves to represent, or remain 'other' and perpetually ambiguous. However, it still offered little to no information concerning how people arrived at their particular self-categorizations, and resulted in a profusion of uncategorized data (Perez \& Hirschman, 2010).

The 2010 U.S. census estimated that $8 \%$ (one in twelve) Americans did not identify themselves in exclusive categories (Perez \& Hirschman, 2009). Another study found that 9 million Americans identify as more than one race (Cohn, 2010). However, census data does not and cannot account for many of the social processes that multiracial individuals experience and perform in order to reach their personal racial identities, and how social construction plays into this. Even self-categorization has the hazard of placing a veil over the complicated variables of mixed race identities (Hitlin, Brown, \& Elder, 2006), and can allow outsiders to group certain racial mixes into singular categories, and project similar experiences onto them. While there are likely to be similarities between groups of similar phenotypic mixes in a cultural sense, most if not all racial experiences comes from social interaction, and can therefore vary in a myriad of ways between individuals. Perez \& Hirschman (2009) argued that personal racial identities are often completely different from racial ancestry. Based on this, it would seem likely that a family racial identity is not necessarily a direct transfer to a personal racial identity, especially when parents and other family members identify as different racial groups that 
possibly maintain varying levels of representation within the family circle. Thus far, there is no singular conceptual framework for collecting data on multiracial identities. This may be attributed to the insufficiency of standardizing or generalizing anything about the multiracial experience. The difficulties involved with generalizing multiracial identity highlights the importance of researching identity on an individual basis with equal attention paid to the process of identity formation, and material used for formation.

\section{Mixed Race Today}

Multiracial or mixed race individuals often live in an existential social milieu where they do not fit with any previously existing racial categorizations in society (Gordon, 1997). In some multiracial families, the only people children may have encountered who look like them are other members of their family unit. Still, mixed race identifications have been increasingly recognized in media, encouraged by a stigmatic sentiment based on physical appearance akin to the troublesome 'jungle fever' of the 1980's or 'waif' fetish of the 1990's. Celebrities like Mariah Carey, Tiger Woods, and Barack Obama brought public consciousness to the issues of identification for mixed race people, but did not truly educate on the process of developing and performing a mixed race identity. Tiger Woods was one of the first celebrity figures in popular culture to identify publicly as mixed race. He coined the term 'cablanasian', or part Black, part Indian, and part Asian. While opening a conversation about mixed-race identification on a public platform, Woods' popularity added stigma towards the multiracial experience by framing it as something that could be neatly packaged in a clever label. As popularity of multiracial celebrities has done little to enlighten the world on the multiracial experience, 
the novelty of mixed heritage is often met with phrases like "mixed kids are always so beautiful" (Callahan, 2013). Because the aesthetic of racial ambiguity has come into style and is considered in many social spheres and media outlets to be beautiful or interesting, a level of exoticism is often placed on the mixed race identity (Root, 1996; Asultunay, 2004), thereby positioning it more as a trophy than a psychological and sociological process that is built in multiple ways. As Senna (1998) noted, "strange to wake up and realize you're in style." (p. 12).

The practice of labeling or naming oneself is often a method of getting social reward, as people are asked and expected to identify themselves racially on everything from driver's licenses to school applications (Milan \& Keiley, 2000), but for mixed race individuals this can be a difficult process. Individuals who possess marked bodies are in a particularly vulnerable position to receive unwarranted stigma, challenge, and inquiry concerning their racial identity (Dacosta, 2007). A marked body refers to someone who has visibly non-Euro-American features, or characteristics that differ from the norm. As Euro-Americanism is often viewed as a normative concept in U.S. American culture, it is rare that those people with perceivably Anglo features are asked to defend their Whiteness (Warren, 2004; Ifekwunigwe, 2004). This is because Whiteness is often perceived as cultureless, naturalized and unnecessary to question, unlike what many minorities and mixed race people stereotypically experience.

Mixed race people who do not identify by their racial genetics can be accused of 'passing', a practice that exemplifies both the various personal identities a person of mixed race may choose as well as the social performance of race. Additionally, 
multiracial peoples' identities are often diluted to a simple transference of genes, whereby if they have a parent of color, they are expected to identify as half that particular family race, whether or not they feel included in it culturally. Because race remains a socially constructed notion, and even though American society recognizes and affirms self-categorization more than it has historically, multiracial people can face accusations of disloyalty to one race or another, or contestations of a their chosen race when asserting their personal identity (Dacosta, 2007). Asultany (2004) wrote that multiethnic identity is often "ignored and translated to mono-racial through the submerging of one identification and the privileging of another.” (p. 20).

Phenotypic ambiguity often makes those of racially mixed heritage feel as if they do not have the physical credentials to fit in with their chosen identification (Dacosta, 2007). Even those who do not choose to 'pass' as something other than their racial genetic inheritance are often asked to perform a type of qualifying trial. During this, their performance of race is often critiqued by both members of the communities they identify with as well as onlookers with phrases such as 'but you don't act Black' or 'there's the Mexican in you.' It is under these circumstances that the social construction of race and specifically mixed race is most visible, and the importance of personal racial identity and family identity most highlighted. Because racial identity lives in the socially learned enactments and performances of race in various social settings, it is important to inquire on the possible communicative processes that might affect it. 


\section{Communication Theory of Identity}

Intersections of societal constructions and mixed race identity have been well theorized, but there still lacks a body of research that specifically looks into possible relationships between multiracial family identities and multiracial personal identities, as well as how those might be communicated from within families. Identity proves to be one of the more complicated performances that most individuals take part of in their lifetime. Additionally, the variety of narrative inheritances that mixed race people receive can encourage that confusion. This may be due to the way in which identity is often produced and maintained through communicative acts, as elucidated on in Hecht's (2004) communication theory of identity.

Social science theorists have long looked at identity as an intricate performance, beginning with work by Goffman (1959) and his concept of 'performing selves' and expanded on by Butler (1990). Goffman (1959) argued that identity is a performative act and is often based largely on what can be perceived on the outside, while Butler (1990) explained identity as something performed through a "stylized repetition of acts" (p. 519). Many aspects of identity cannot be fully disentangled from the physical body and its communicative habits, which are often seen in performance of narratives. Because of this, some scholars argue identity is understood and actualized through communicative acts of the body, and contested, claimed, and maintained through the highly social act of performance (Taylor \& Littleton, 2006). In this sense, the act of communication is a constant production and reproduction of identity. 
The communication theory of identity (CTI) offers a supporting theory for this concept. CTI breaks identity into four major frames, including personal, relational, enacted and communal identity (Hecht, 1993; Jung \& Hecht, 2004). The personal identity refers to individuals' self-concepts or how they see themselves when they look in the mirror, or consider their actions. In the personal frame, identities are meanings inflicted on individuals as an object in social situations (Jung \& Hecht, 2004, p. 79). In addition, they are meanings attributed by others to personal selves, and enactments of both expectations and motivations (Jung \& Hecht, 2004, p. 79). In summation, a personal identity frame stems from self-concept, but does not disassociate self-concept from the influences of certain social situations, as personal identities are formed through communication with others.

The enacted identity is the performed side of identity, or the version of individuals that is performed during communicative acts with others. When considering a 'performed' identity, it is important to note that the performed identity is still considered to be an actual aspect of the identity and not just a momentary performance. As Jung \& Hecht (2004) put it, “enactments are not mere expressions of identity but are considered identity itself" (p. 266). This differs from the personal frame because while the personal frame is based in self-cognition and is somewhat spiritual in conception, the enacted identity is what is performed to the outside world.

The relational identity is a multi-level phenomenon that helps to describe how certain relationships influence identity. It is a comprehension and internalization of how people internalize the views of others or rather, how others view an individual. A 
relational identity refers to both peers' views of an individual, and to the relationships between how multiple identities within a certain person are enacted and understood. For example, someone can simultaneously be a child and a parent, or a doctor and a patient. The last frame outlined by Hecht (1993; Jung \& Hecht, 2004) is the communal identity, or how collectives define their identity. This is particularly important in analyzing mixed-race identities in pertinence to a small-group culture like family, or a large-group culture like the category of mixed race in the United States.

It is also important to note that with all these frames of identity there is much overlap. While they work as different lenses through which to view identity, the identities themselves flow and merge into one another. One may have a racial identity from a personal identity frame, yet this cannot be completely disassociated from the racial identity enacted in a relational frame such as performing being a child, or communal as seen in family performance of racial identity. Hecht's CTI is especially relevant to multiracial identification as it takes into account both the fluidity of identity as well as the multitude of frames through which identity can be conceptualized. Within all of these frames, it is important to note that the identity is built and maintained through communicative acts from family, strangers, inner narratives, and reflection. Because those who are more than one race often have more than a few communal identities they may feel a part of, or one very complicated communal identity, there are likely to be specific communicative acts (such as narrative sharing) that help to form and maintain their group membership in a diverse group, as well as in several different groups. CTI's relational identity frame is an important reminder of the multiplicity of identities that can 
be present at any given time within one person. For example, a child may be a Mexican daughter at her father's house while maintaining her identity as an American mother in another setting. The personal identity frame is rooted in self-concept or how mixed race people might see themselves, regardless of their genetic makeup or how their family identifies.

The purpose of this study is to look for possible connections between the personal identity frame and the communal identity frame through the medium of narratives communicated in the context of the familial community identity. The performance of these narratives and the recall and re-performance of them can be viewed as enacted identity, while the relational frame is a reminder of the fluidity of identity depending on context, and how the demand to claim one racial identity or another in mixed race families can be infinitely complicated and involve a multitude of factors.

\section{Narrative Inheritance \& Storytelling}

Based on Hecht's $(1993 ; 2004)$ work on identity and communication, Langellier and Peterson's (2004) study on narrative sharing in families, and Goodall's (2005) terminology, this study will use the term 'narrative inheritance' to refer to the inherited stories that younger generations often receive from older generations. While previous research on the topic has been largely ethnographic in nature, it still serves as an ideal packaging of the complicated transference of narratives within families.

A basic example of a narrative inheritance can be found in the instance of family legacies. Family legacies are usually found in stories that are told over generations (Stone, 1988) and often culminate in a certain aspect of familial identity that the receivers 
of the legacy can either accept or reject (Thompson, Kellas, Soliz, Epp, \& Schrodt, 2009). Researchers found that an important aspect of adulthood identities was found in children's choices to embrace, reject or extend their family legacy, given to them as a narrative inheritance (Thompson, Kellas, Soliz, Epp, \& Schrodt, 2009). Because of this, the existence of a legacy is not necessarily indicative of the personal identity, what individuals choose to enact outside family culture, or reproduce when beginning their own family.

Family stories often do not occur in canned sequences based on classic story archetypes (Langellier \& Peterson, 2004); narrative inheritance can occur in small conversations, collective memories, or even historical instances that were mentioned once but remembered by the younger generation of listeners. Hirsch (1998, as cited by McNay, 2009) used the concept of post-memory to explain the experience of people who grew up around narratives of things an older generation may have experienced, and how the younger member of the family can be somewhat dominated by traumatic events that are often difficult to understand if not spoken about regularly. In this instance, it is evident that absent narratives can be detrimental to identities in all frames. Additionally, it shows that traumatic or difficult experiences of other generations trickle down by way of narrative inheritance to become a potential part of a child's identity. It would seem likely that under this assertion, stories about race-related hardship may be an integral part of identity formation in multi-racial families, and important to speak about.

Post-memory also appears in research about racism wounds in African American families (Rosenblatt \& Wallace, 2005). Here, the researchers found that narratives about 
deceased family members often included reference to instances of racism in the deceased life, and how that person may have helped them deal with racism. This research shows the relevance of lived experience concerning race issues that may be remembered and retold by younger generations. While the study did not articulate specifically how narrative inheritance concerning race took place (whether it was observed in the physical or listened to through stories) it did articulate the importance of race issues in remembering the life of a minority individual.

Tyler's (2005) work is an example of narrative inheritance used within qualitative research. Her study with mothers of interracial children and interracial women aimed to uncover the ways that they spoke about concepts like biological and cultural inheritance, belonging, descent, ancestry. Her research was guided by interest in how individuals from racially and ethnically contested situations chose to go about identifying themselves and their children, and how they reached the point where they felt comfortable with their claimed identity.

One of her participants, an adopted biracial woman named Sandra, remarked on finding her father and listening to the stories he told her daughters about coming from Antigua. This participant's conception of interraciality came from an inheritance of Black cultural knowledge from her father, and knowledge of her culture and ethnicity helped her learn to associate and identify herself with Blackness. Another participant in Tyler's study named Nazmi talked about the inheritance of Muslim identity and the need for her to continue cultural practices and dialogue of Islam with her interracial children. Tyler 
identifies Nazmi's narrative work as a way of making permanent her children's Muslim identities

Narrative inheritance is the stories, narratives, and snippets of memory that have been 'given' to children by members of the family about themselves and other family members. The amalgamation of these memories arguably creates a cohesive aspect of family identity and can reflect many of the values, norms, important moments, and methods of identification that both ancestors and other family members use to perform their identities as well as share them with their children. Messages about race are particularly important in narratives, as they prepare children for the culture they were born into (Joseph et. al, 2013) as well as possibly how to assert, hide or deal with their race or races both within the family as well as out in society. As seen in Tyler's (2005) research, the act of imparting narratives to children can help to secure a cultural or racial aspect of identity that the family wishes their child to afirm, and make part of their personal identity even away from the family.

Mishler (2006) argues that individuals use narratives to 'restory' their pasts. In this sense, narratives in families may be used to not only work towards cohesive individual identities but also to share historical events that may have contributed to one generation's sense of identity, thereby passing it on to the younger generation to use as a framework for their own identity by sharing beliefs and values in a racial context. Both receiving and sharing narratives can also act as a way to enact the variety of identities a mixed race person or an interracial family may have present at any given moment. 
Work in narrative therapy has expressed the necessity of developing a 'personal narrative' (Milan \& Keiley, 2000). A personal narrative is a particular set of stories both present and past, which can be helpful in multiracial families specifically. However, while it is changing rapidly, some children have an entire school career without seeing pictures of other interracial families (Milan \& Keiley, 2000). This can result in confusion and difficulty in conceptualizing a family (communal) identity or creating a personal one. Arguably, this personal narrative is a way of performing, maintaining and creating a personal identity, and is formed largely through the relational and communal frames of family identity, and the receiving of an initial narrative inheritance to help guide the process.

\section{Storied Resource Perspective}

The storied resource perspective positions narratives as formations guided by socio-cultural interaction and conventions while still maintaining an element of individuality (Smith \& Sparks, 2006). Somers (1994) argues that connections between narratives and identity must move away from being considered a method and become more of an ontological reality, and that we "come to be who we are (however ephemeral, multiple, and changing) by being located or locating ourselves (usually unconsciously) in social narratives rarely of our own making." (p.606). The perspective views narrative as thoroughly important in the identification and reflection of personal selves, but also takes into account the socio-cultural factors that may have had a role in a person's dealings with their narrative, such as cultural meta-narratives of war or politics. 
Also important to this perspective, is looking at narratives as things that are performed or actively done. In reference to Butler's perspective of identity performance, this conceptualization allows for the contextual social act of telling a story or 'doing' storytelling. Unlike perspectives that draw more from the psychosocial field, narratives are seen as interwoven with both greater society and an individual's past, as well as the particular conversation it arises within. Somers (1994 as cited by Smith \& Sparkes) wrote that these narratives draw on a store of cultural knowledge, personal experiences and others' stories from which to create a narrative that cannot be completely disconnected from a person's sense of identity and enactment of such. Therefore, the narratives that we speak are guided by a larger entity than ourselves, and the process of absorbing and performing narratives is another way to look at performing a personal identity. What people choose to integrate, remember, and share is both reflective of a greater social process and some of the individual choices of 'doing' identity.

\section{Storytelling in Families}

According to a storied resource perspective, all narratives help guide a personal narrative, and one of the integral sources of these narratives may come from the family community. Storytelling and performance of family stories that may turn into a narrative inheritance are part of how individuals make sense of the world and learn how to process and act on the events in their lives (Kellas, 2005). This is because storytelling serves as the vehicle for a narrative inheritance, and is often completed in a process that is contextual, based both on who is doing the storytelling and on what kind of setting they might be in. 
Often, storytelling results in narratives that are collections of stories and moments and are made sense of through the process of joint storytelling (Ballard \& Ballard, 2011). The joint process can shape the family identity as well as provide space for enactment of individual roles within families (Kellas, 2005). This process has been shown to be integral in dealing with difficult experiences, forming and inscribing family identities, or even allocating and confirming individual's roles within the family.

Just as individuals may enact or reject a narratively inherited legacy or family identity (Thompson et al., 2009), the process of doing just that is often actualized in the process of family storytelling. Langellier \& Peterson (2004) found that family storytelling often included stories of rejecting a family tradition, changing a name or challenging familial norms. This comes into particular pertinence in relation to interracial families who have often experienced social and familial difficultly simply to become a family in the first place (Dacosta, 2007), let alone begin to form a cohesive family narrative or legacy. As Byrd (2006) described, part of constructing biracial identities involves a resolution of difficulty faced by a biracial union, and a joint explanation to children that varies throughout developmental states of their lives. In these instances especially, the element of storytelling becomes a constructive force that can help a multiracial family make sense of the difficulty they have faced previously by becoming a family, and defending their chosen family identity (or individual identities) in the advent of social opposition. It is possible that there are certain narratives that may be part of some family members' personal identities that are never allowed into an enacted identity, so therefore never become part of the family or communal identity. The process of sharing narratives 
in families can be a selective process, whereby members choose which stories they wish to keep alive and which they wish to let go of or avoid passing on.

Kellas \& Trees (2006) found that supportive families often co-created a single integrated story with a clear framework and an incorporation of one another's perspectives throughout the performance. In addition, they argued that with a joint process, family members could participate in creating a family identity by assigning environment, characters and settings that help to tell a story that might not even be their own. Koenig Kellas (2006) found that storytelling processes are often indicative of relational processes that occur in family settings, especially but not limited to, who gets to talk, when, and whose views are incorporated most often. Koenig Kellas' study adds an interesting element when discussing racial identity as it raises the question as to if more dominant family members who receive more talk time and control of family narratives may have a greater chance of passing on a narrative inheritance that reflects their life experiences with race disproportionately.

Soliz, Thorson, \& Rittenour (2009) expressed the need to further research the specifics of family communication and identity for multiracial and multiethnic individuals, as the majority of research already produced looks at African American and European American couples and their children and fails to include other multiracial categories, which are seen to be growing rapidly. While their research certainly laid groundwork for the field of multiracial family communication, it also culminated in a quantitative study, through which it is difficult to understand the range of stories are 
shared in multiracial identity building processes as well as what they might mean to the individuals who receive them.

Multiracial family narratives and storytelling allow for narrative inheritance, which helps construct personal and familial identities. Multiracial families have a larger chance of narrative variety about race, as it is likely that parents have separate cultural experiences in handling it, and different physical appearances that may have garnered varying degrees of societal narratives concerning race. This paper aims to gather information on how the specifics of racial identity are inherited, constructed and coconstructed based on multiracial children's account of narratives received and shared in their families. Communication in families often differs depending on an individual's perceived sense of difference or affiliation with one another (Soliz et. al, 2009) Because of this, Soliz et al. (2009) expressed the need to further research the specifics of family communication and identity for multiracial/ethnic individuals, arguing that the processes of sharing narratives was important for solidarity in multiracial/ethnic families especially, where individual identities have the propensity to differ from both one another and the family identity. As Tyler's (2005) work showed, some parents use narratives as a way of making their child's identity both cohesive in a familial sense, and closer to their own individual identity.

Because multiracial identity cannot be reduced to to an amalgamation of bloodlines and a simple reflection of genetics, it is difficult to understand the processes that may be unique to mixed race families through census data or other forms of quantitative study, as matters of identity are often more effectively inquired on from a 
qualitative standpoint. Perspectives of narrative and identity formation based on work by Somers (1994) show that identity is inextricably linked to a variety of narratives, ranging from societal to personal, and that the act of performing or 'doing' those narratives is an act of both creating as well as simply 'being' an identity. Hecht's (1993) Communication theory of identity breaks identity into four frames, and asserts that identity is formed through acts of communication, and can vary depending on the context. Additionally, CTI reminds us that several identities can exist simultaneously in one person at any given time, just as several different narratives can be given and used as guides for identity depending on a myriad of familial and personal factors.

Langellier and Peterson (2004) offered insight to the communicative habits revolving around storytelling in families, and the mode in which a narrative inheritance may be given to children in families. While all these processes are complicated and involve infinite variables for any individual, a mixed race person has the possibility of facing even more incongruent narratives just by sheer variety what is received, or by an inability to counter the narratives given to them by the world outside their family with the ones received inside their family.

The narrative inheritances shared in multiracial families are an important tool in sculpting identity as well as studying identity, and while they cannot necessarily offer a completely uncompromised picture of an individual's personal identity, they can help to articulate connections between familial, personal and relational identities through the mode of narratives as an enacted identity. 
RQ1: What kind of narrative inheritance do people in multiracial families report receiving about race?

RQ3: What factors are potentially related to the process of inheriting narratives in multiracial families?

RQ2: $\quad$ How might these narratives relate to reported personal racial identity? 
Methods

\section{Participants and Procedure}

Participants were recruited from a Northwest city using snowball methods and word-of-mouth. There were 8 males and 4 females of ages $18-30$ out of a target sample size of 12 interviews, all of whom fit the criteria for this study. Efforts were made to stay in a 15 year age range, as participants from different generations were likely to have different modes of approaching multiracial identity due to shifts in socio-political climate. Additionally, the age range was chosen because those who were beyond their teenage years were more likely to have a developed sense of personal identity than younger people. Eight of the participants were enrolled in the NW university communication department where the study took place, and 4 were from outside of the institution. This was done in effort to learn whether identity talk differed between those who were currently in academia and those who were not. Interviews lasted anywhere between 20-45 minutes, depending on the comfort of the participants, their focus on the questions, and the general flow of the conversation between interviewee and interviewer. Participants were recruited on a basis that they were over 18, and self-identified as possessing two or more races or ethnicities, though they did not necessarily need to personally identify as multiracial. There was a wide range of races represented in the sample with participants who identified as Vietnamese, Chinese, Hispanic, Filipino, Black, Creole, White, Guatemalan, etc. Under no circumstance were any participants’ chosen identities contested or disputed, as this study is deeply rooted in theory that views race as a social construct (Omi \& Winant, 1994) as opposed to a genetic determinant. 
This was seen in one participant who identified as almost completely Black but still saw being Black as being mixed, due to mixing that happened in previous generations.

Participants went into the semi-structured interview sessions with an understanding that they would be asked to speak about the experience of growing up multiracial, as well as any recollections they may have about race-based discourse within their family. Additionally, they were asked if their family told many stories, and if they remembered any of them (see Appendix A and B for full interview protocol and questions). They were also asked to pick their own pseudonym that would be used for the purpose of this study before the audio recorder device was turned on. Interview location was left up to the participants to choose based on their own comfort. Interviews took place in a variety of settings ranging from the communication research collaboratory of the researcher's Northwest institution, to the participants' living room floors. After each individual interview, every participant was thanked and given a $\$ 10$ gift card as a token of gratitude and appreciation for their time and for the privilege of receiving their narratives.

\section{Semi-Structured Interviews}

This study employed semi-structured interviews to collect all data. Interviewees were aware of the general subject of the interview and were informed that the purpose of this study was to increase academic knowledge on multiracial identity and family narratives. Semi-structured interviews allowed the space for participants to speak freely about their experiences with race, while still guiding the subject matter towards multiracial experiences and family communication. Wengraf (2004) noted that semi- 
structured interviews that allow for a participants' free rein of narrative run the risk of being diluted by the participant's self-presentation. While this is noted, a partial purpose of this study is to look at how multiracial people see themselves, or wish to perform their personal identity, making Wengraf's (2004) critique a non-issue.

Because identity is viewed as something that can be enacted in multiple frames as noted by CTI (personal, relational, enacted, and communal) and enacted by multiple forms of narratives, a large part of the decision to use interviews was based on the view that the enacted identity is still part of a real identity, and not just a performance. How participants chose to enact their personal identity and what they had to say about their family identity and narratives they attribute to their family may have observed connections that could help make sense of how narratives affect identity.

Lastly, semi-structured interviews were deemed the best method to collect data because they allow for members' meanings to be articulated and observed. Other methods such as quantitative analysis could not obtain spontaneous reports of remembered stories and would lack the advantage of the presence of participant voice. The issue of members' meanings arises from Blumer's (1969) work on social interactionism, and refers to how members of the group identify, understand, experience and describe certain concepts relative to their lived experience. Members' meanings help to avoid biased descriptions of certain phenomena non-native to the researcher. In addition, the application of members' meanings as a research frame helps to avoid a topdown approach where many concepts are pre-defined based on how a specific culture outside the research subject understands them (Blumer, 1969). 
In relation to this, the researcher's positionality should be noted. Dace \& Mcphail (2002) used the concept of implicature in research as a way of encouraging empathy between self and other, and in this case, between researcher and participant. Implicature is based on the idea that humans are interrelated and interdependent, and the reality we exist in is defined more by togetherness and wholeness than separation. Implicature is specifically important to recognizing positionality in the collection of narratives because it serves as a reminder that the researcher and participant are not necessarily separate and completely objective entities.

As a person of mixed race growing up in the United States, many of the experiences encountered in the interview mirrored experiences of my own. However, due to the immense variety between different racial backgrounds and the cultural metanarratives they carry with them, I was not looking for anything specific to match my own experience of racial narratives. Growing up Black, Japanese, and White certainly allowed me to be privy to certain stories and experiences that were most likely not specific to just my own family however, as family storytelling comes in candid sequences and is contextually based, I did not have a thematic assumption of what would be talked about in terms of race in other multiracial people's families.

This being said, the notion of implicature still demands that I look at myself as imbedded in the research, and part of it merely by the act of conducting interviews. It is important to situate myself as a researcher within the data, and reflect on the possibility that my specific lens may have played a role in the drawing out of themes. My position as a multiracial person in the same age range as the participants and my extensive library 
research on the subject allowed me unique intuition as to what questions might have been more relevant to ask than others, as well as what might have been seen as offensive. I believe this gives me unique insight through which to perform my job as a fluid and adaptive interviewer in the course of conversational interviews with better finesse than someone who is perhaps not related to the subject matter by lived experience. My positionality allowed me to conduct casual and relaxed interviews and increased my sensitivity to some of the narratives that were shared, though due to the uniqueness of every multiracial person's experience I was able to avoid applying my own experience to theirs in a way that dominated their voice. Instead, I could empathetically guide interviews to highlight their voices, while still viewing the data objectively through the coding process.

\section{Grounded Theory}

Semi-structured interviews were analyzed using grounded theory as the primary tool. A grounded theory approach is arguably the method most faithful to emic-based qualitative methodology and can be used to study possible similar characteristics or themes across a group. Grounded theory entails a naturalized context-driven focus where concepts, categories and evidence create a framework for comparative analysis that later can be extended into a formal method of generating theory (Glaser \& Strauss, 2007). Matza (1969) defines naturalism as relying on procedure that could be replicated exactly but with a viewpoint that is "committed to the method of science" (p.4). Essentially, naturalism desires to remain 'true to the nature' of whatever is being studied (p.5). With this in mind, it seemed appropriate that memories of narratives were gathered from 
people narrating. Additionally, this study uses the scholarly evidence that narratives help create identity, so any act of narration that is observed is still considered to be a production or reproduction of identity maintenance.

As noted by Emerson, Fretz and Shaw (2001), data collected using this process does not necessarily have intentions of debunking or disproving previous research on the subject, and does not necessarily need to discount previous literature on the topic as a starting point. McCracken (1988) argued that a review of previous literature and scholarship cannot be ignored, and could be considered irresponsible if skipped over. While grounded theory purists like Glaser \& Strauss (2007) might pronounce this as an interference with the naturalization of data, an approach more like Wengraf's (2004) is extremely useful, where some basis of understanding is necessary before beginning the categorizing process. Because the topic of mixed race identity is fairly popularized across a wide variety of media and carries with it both historical tensions and socio-political arguments, I felt it necessary to review literature and other personal accounts of mixed race individuals extensively before accessing the data.

Grounded theorizing is used to effectively investigate how "members actually classify events." (Emerson, Fretz, \& Shaw, 1995, pg. 152). As previously stated in juncture with members' meanings, this helps to negate the interference of what a researcher identifies and understands as an observer and member of society. Because of this, terminology used must reflect the terminology and understandings of the group members. While this study uses the terms of 'narrative inheritance' and 'storytelling' to help frame the study, participants saw much of their family communication in terms of 
'this one time she/he told me' or other more colloquial phrasings. This is why the paper was written with special attention paid to including as much participant transcript as possible, in order to allow participant ownership of narratives and avoid overwhelming their stories with an academic frame and terminology.

\section{Open Coding}

This paper used open coding stemming from analytic induction to pull relevant and recurring themes about racial dialogue from the interviews. Analytic induction was originally proposed by Znaniecki (1934) as opposition towards methods that pull conceptual categories from an already existent group of cases, or data. Instead, analytic induction begins with an idea of what aspect of the phenomenon needs to be explored (Becker, 1998).

The open coding process was used to uncover some of the potential meanings, themes, and patterns the interview data held. Open coding is the process of opening up the data set, and breaking it down into parts that help the researcher look for reoccurring themes and patterns (Strauss \& Corbin, 1998). Focused coding (Emerson, Fretz, \& Shaw, 1995) was employed for the last 4 interviews, as the first 8 allowed a saturation of themes relating to the research questions. Saturation occurs when this study has collected and coded enough data that new themes, patterns, and categories fail to appear out of the data anymore (Glaser \& Strauss, 1967).

Following this, relevant narratives were organized onto physical storyboards, with each participant's narratives concerning race organized on a separate board. The storyboards were then re-coded to check the accuracy of the original coding, and main 
themes for each board were organized and pulled. Finally, themes between boards were organized on a code sheet with relevant transcript lines accompanying evidence of specific themes, and overarching themes that were present across the data for all research questions were finalized. 
General Results

My initial thematizing of the data resulted in three primary themes in relation to RQ1, which asked what kind of narrative inheritance multiracial people report getting from their families concerning race. Themes that arose included 'racism narratives', 'hardship narratives', and 'cultural pride narratives'. Narratives concerning racism were largely based on family members' experiences of navigating a racialized world, as well as advice and instruction on how to deal with instances of racism.

'Hardship narratives' most often came from parents or older generations and involved historical trauma, such as instances of poverty or war. While racism could have been coded under this theme, the amount of racism narratives reported was so large that it seemed important to pay attention to the specificities of them. 'Hardship narratives' were found to be shared as a source of pride in some cases, and hidden or silenced in other cases.

Narratives about cultural pride were most commonly expressed in familial willingness to educate one another about race and any cultural norms that accompanied it. These narratives often affirmed pride in heritage and racial solidarity.

RQ2 asked what kinds of factors potentially affect the process of inheriting narratives in multiracial families. Themes that arose in relation to familial construction of narratives included 'divergent family structures', 'who talks', and 'language barriers', 'Divergent family structures' referred to families who had experienced divorce, separation, adoption, or family disagreements. The data showed that all of these factors very likely quieted or blocked certain family narratives due to distance, amount of time 
spent communicating, or children's willingness to accept or reject a parental narrative. The theme of 'who talks' showed that the sharing of narratives was likely affected by who held talking power within the family, who the child was more likely to listen and speak to, and who was simply more verbose. These themes reflected Koenig Kellas's (2006) work on family dynamics and dominant communicators and how much talk time they hold. The last theme present for RQ2 was 'language barriers'. 'Language barriers' appeared to play a role in racial identity development as the way some family narratives were shared involved a language other than English. Participants' inability or ability to speak the language of their extended family or their cultural mother tongue appeared to affect whom they could receive narratives from as well as how they connected with that side of their family.

RQ3 asked how narrative inheritances might relate to reported personal identity expression, and was highly dependent on themes from both RQ1 and RQ2. Data indicated that multiracial children had many different ways of identifying themselves based on a myriad of factors both within the family and outside of it. Still, those who reported receiving multiple race based narratives from a particular parent in their family tended to identify themselves similarly to that parent's race. Those who did not receive many race narratives due to language barriers, separation from parents of color, or having one parent's narratives disproportionately represented, tended to identify as more EuroAmerican and less as their minority side, or in cases with two parents of color, as the more communicatively dominant parent. 
It becomes clear the important role of narrative inheritance in multiracial families when looking at the results for all research questions simultaneously. Because of the multiple different kinds of cultural and racial narratives that were likely to be present, the process of receiving and building identity from stories appeared to be easily affected by a wide range of factors depending on the individual family. This process made the likelihood of losing certain race-based family stories perceivably higher, and the decisions about forming personal identity more complicated.

Participants who had a large narrative inheritance concerning race appeared to be less confused about their background and more confident in their own racial identity. Additionally, there were more cases of mixed race pride in participants who acquired large amounts of family narratives from both parents, whereby they were perceivably proud of all parts of their racial background. 


\section{Racism Narratives}

\section{Parental Racism Stories}

Narratives involving racism were the most frequent, as all participants had experienced at least some dialogue concerning racism and almost all of them had shared narratives with their family members about racism.

There were several main factors that appeared to contribute to the construction of racism narratives. These included multiracial children's realization of race and race issues through social exposure in school, participant inquiries of race as a result of exposure, level of racial ambiguity in the physical appearance of the child, and the racial makeup of the environment where the participant grew up. Participants who acknowledged growing up in a predominantly Euro-American social environment reported more narratives of race-consciousness coming from social situations outside the family. These were often then talked about within the family after the child brought it up. Additionally, the parent who was a parent of color was more likely to engage in racism talk with children than a Euro-American parent, but this was also offset by factors such as family discord (divorce, separation, death, family feuds) and who the participant felt closer to, as well as who was the more verbose parent.

One participant who called herself Ashley and identified as mixed or half-Black and half-White was given a comparatively large repertoire of stories about the racism that her Black father faced, as well as instances her parents faced together in their interracial marriage from both outside and inside the family. While her father did not acknowledge 
racism difficulties as often or openly as Ashley believed they might have occurred, he did share some.

Figure 1 - Interview 2, Lines 162-173

Interviewer: Do you remember anything in particular your dad told you [in regards to race conversations]

Ashley: He's such a prideful person he doesn't talk about it much it, but I think just within the work place he's faced discrimination. There would be just little slide comments and um, not getting certain opportunities, he actually got into um, he'd just seen Fruitvale Station and he um, was picking up my mom and he just parked in a spot that wasn't a spot but it was out of the way, and he had his flashers on and he was just waiting for her to get out of the grocery store and a woman walked past, she was fairly older and she said " Oh that's not a parking spot." and he said "Ok." and um, she kept walking and she said "These n-words will never learn." And this was literally just know, a few months ago and he said...he was just like wow, he was pretty upset, especially since he had just seen the movie Fruitvale Station he almost went off on her but, he really had to hold his tongue so, yeah.

Ashley's story references the cultural backdrop of a film about police brutality and race issues. Furthermore, Ashley received stories of the racism that came from other members of her family, whereby members of her Euro-American extended family contested her mother's union to her father, serving as a pertinent example of some of the trials that multiracial families face even in their inner circle. 
Figure 2 - Interview 2, Lines 138-145

Interviewer: Did she tell you of any certain instances [of racism]?

Ashley: Oh yeah, she said she was kicked out of her house when she was about 19, she actually went to PSU, so she was supporting herself, about like 19-20, or I guess she was like 20-21 when she met my dad so more 20-21, um, and they would call her like, an n-word lover and 'go suck black...' you know and um, there was a lot of stuff that was happening, even just random people, her and my dad were walking around at like a farmer's market and somebody said "oh there goes the neighborhood." But yeah you know, it was pretty bad, and this was you know in the 80 's or late 70 's.

Ashley's account acted as a pertinent reminder that contrary to Goodall's (2005) articulation of narrative inheritance, narratives that are received often happen in realtime, yet still enter a child's repertoire of stories. Ashley's firm self-proclaimed identity of half-White and half-Black was likely affirmed by not only her physical appearance but also her close identification with memories of her father's stories of what it meant to be Black. Ashley was one of the few participants who received racism narratives from a Euro-American parent as well, and having racial narratives that implicated both her parents' races may have helped in her secure conception of herself as mixed-race, without the necessity to privilege one race over the other.

Ina, who identified as half-Lebanese and half-Mexican though felt more culturally Mexican, remembered an instance of racism that happened when she was eleven at a water park. In this narrative, a man cut her family in line and when called out on it, called her mother a "Stupid Mexican" (see: Interview 7, line 200).

This was possibly a story that was retold jointly within the family as Ina could recite it in great detail despite her young age at the time of occurrence. This supports 
Kellas \& Trees's (2006) assertion that storytelling in supportive familial environments often results in a single integrated story. It is possible that the sort of perspective sharing necessary to remember a family member's narrative not only contributes to family identity, but also to personal identity development, as the ability to relate to racial trauma familiarizes the child on what it means to be of partial Hispanic descent. Even with the negative connotations associated with racism narratives, this narrative about racism seemed to increase Ina's racial solidarity and protectiveness of her mother and the racial category they both shared.

Ina also remembered another instance that her mother had told her about facing racist remarks, based in the racist implications of grouping all Spanish speaking people into a singular group.

\section{Figure 3 - Interview 7, Lines 216-230}

Ina: Yeah my mom has told me one time that she was with her friend and they went to the bank together and it was in Oregon and her friend is actually Caucasian, White American but she knows how to speak Spanish and they were speaking Spanish with each other outside the bank and a guy walks out and he said "Stupid beaners" and at the time my mom was just like “Just let it go. I don't want this guy in my face.” It just really upset her because she was like "My friend's not even Mexican. My friend just knows how to speak Spanish. How can you say that to people when you don't even know where they're from?" So that was upsetting to her. She told me about then and I couldn't believe it either that somebody would say something like that especially when you don't know where people come from. She could've not even been Mexican. My mom could have been from Chile or Venezuela or somewhere else you know? Spain?

Ina's open communication with her mother was evident throughout her interview, as well as the perspective sharing she employed in family narratives. Through her stories, 
it is evident that in empathizing and reflecting on her mother's narratives, they became part of her own perspective and worldview about race and specifically her own race. An interesting aspect about Ina and Ashley's memory of racism narratives is that some of them were based on events that had happened within their lifetimes, as opposed to historical accounts of archaic racism. Both women appeared visibly saddened and disgusted by the events their parents had experienced, and while Ashley began the interview identifying proudly as mixed race, she admitted that the racism her father faced made her dislike the White part of herself at times. Root (1992) argued that multiracial children sometimes reject the less privileged portion of their identity. However, Ashley served as an exception whereby the privileged part of her identity was seen as negative, as it made her feel as if she was connected to something that hurt her father. While storytelling can often result in family identity becoming part of personal identity (Thompson et a., 2009), it can also result in a rejection. Still, the presence of Ashley's Euro-American mother in some of her father's racism narratives was likely to have offset her need for complete removal from the White side of herself, in spite of her frustrations with some of the historical connotations of Euro-American cultures.

Another participant Bob, who identified as half-Japanese half-White of Italian lineage also remembered being told about some of the racism his father faced growing up Japanese in a predominantly Euro-American town. The conversations had arisen when Bob began to face racist jokes at school. Similar to many other participants, much of Bob's racial consciousness began as a result of contact with peers in a social setting. The relational identity as described by Jung \& Hecht (2004) is seen here in conjunction with 
evidence of race as a social construct (Omi \& Winant, 1994), whereby awareness of racial difference was often unimportant until interactions in a social sphere make it a topic of interest. While Bob's home identity was as a son and a brother, his school identity was 'the Asian student' in a social setting dominated by Euro-American students. Bob had a parent primed and prepared to give him both narratives of racism and instruction on ways to deal with racism in a healthy manner, once he inquired. This likely helped to secure his identity as someone of Japanese descent, as racism that he faced opened the channel through which he could inherit stories from his father. While racism is rarely implicated in a positive narrative, Bob's father's stories gave the two of them the opportunity to communicate on common ground about their shared racial group and how to deal with a racialized society. Additionally, it may have helped Bob understand his own experience and place it within a larger narrative that not only connected him to his family's stories but also to a larger societal narrative. 
Figure 4 - Interview 3, Lines 215-236

Interviewer: Did you ever talk to your parents about [the racist jokes]?

Bob: Yeah. Oh, yeah. My dad gave me a lot of advice because my dad is approaching 60 years old. He's retired but when he grew up and when he was in grade school, there was a lot of tension for Japanese-Americans. He was - like, he went to school.

He grew up in Sandy and out there in Sandy when he was in school he remembers having to fight kids just because they would be all over him for being Japanese. It was after the whole war kind of situation but these things were still pretty tense.

He would fight kids just so they would stop picking on him. Kids would just do all kinds of horrible things to him just because he was Japanese. I remember talking to my dad and kind of reflecting on that, kind of making the distinction that hey he was there were physical moments for my dad growing up versus I mean, at least it's only verbal. It's things that I can kind of tune out.

Obviously, it has an effect on me but I want to be strong like my dad. He didn't - it wasn't necessarily always good that he had to get physical but I really admire my dad for standing up for himself and I wanted to do that but the best way that I can stand up for myself was by taking his advice and just kind of trying to tune it out and not get into too much trouble.

Bob's story was consistent with Crawford \& Alaggia's (2008) findings, where parental understanding of race issues was important in their ability to support and assure bi-racial children, and that children whose parents who lacked an understanding often grew frustrated and felt misunderstood. As Bob's father had grown up in a similar community to Bob, and identified as being a minority as well, he was able to have supportive two-way conversations with Bob where his own racism narratives emerged and helped him relate to Bob, and where Bob was able to inherit both rules for the social world and family history simultaneously. 


\section{Parental Preparation for Racism}

While most of the narratives shared about past racism could be framed as parental preparation for racism their child might face (as in Bob's case), some parents specifically made a point to make sure their child knew of the various injustices that they might face. While Bob's father set an example for standing up for himself upon Bob's inquiry to racism issues, other parents gave advice without being asked.

A participant named Simba who identified as Latino, Hispanic, Filipino, and Native was given preparation less from his parental figures' lived experience narratives and more narratives of how the world works, and what their child might have to keep in mind about it as he moved through society. Simba's mother let Simba know early on that things might be different for him than other kids due to his family's racial identity, and that this was something he needed to be reticent of when moving through a racialized world. 
Figure 5 - Interview 1, Lines 29-40

Interviewer: When you say culturally Hispanic what does that mean? How do you see that?

Simba: Just, I just feel like I was very installed on like... it had been instilled in me because who was raising me was not from this country. It was very put in front of me that I'm not American and that, I am Hispanic, and the opportunity, er, that, there is meaning behind that, that doesn't make you different but it does make you different in a way...

Interviewer: Do you remember any specific instances where it was talked about?

Simba: ... Yeah. My mom used to always... when I was growing up she's always... I mean I don't know how I feel about what she talked about now but I remember growing up and her saying you know like people, some people aren't going to treat you the same way and da da da because you are like this and because of this and that.

While Simba had used multiple different personal racial identities throughout his life, the Hispanic side was always present first and foremost. It is likely that receiving narratives about the social difficulties that his racial background carried with it helped to cement his enactment of Hispanic identity as well as prepared him for racism he might face based on this identity. In this instance, it seems that racial identification may sometimes come from the need for racial solidarity in the face of oppression. This was also present in another participant named Four's recollection of narrative inheritances. Four identified very firmly as Black though mentioned he was of Creole descent. When asked if his family ever talked about culture, he responded with a memory of a racism preparation narrative from his parents. 
Figure 6 - Interview 5, Lines 182-189

Four: Like when I started driving, my dad always used to tell me, "If you get pulled over by the police, keep your hands on steering wheel, don't reach for your license or nothing like that until they tell you to because you're already Black, so they might confuse you for reaching for a gun.

And if they say they thought you reaching for a gun, then they can -- nobody will bat an eye about it. Just a lot of it was just keeping me out of the streets when, making sure I hang around the right people because my parents always say, "Your first offense is being Black."

In a study seeking to look at racial socialization messages of African American parents, Thomas, Speight, \& Witherspoon, (2010) found race related stress experienced by parents seemed to be the best indicator of likelihood to racially socialize their children, possibly from recognition of the need to protect their offspring. Based on this, it is likely that both Simba and Four's parents experienced racism in their own lives and felt a need to educate their children on some of the struggles that they might face in society. The African-American and Hispanic communities Simba and Four came from have faced a large amount of obvious political and social oppressions in the United States. It would seem probable that parental lived experiences would have been used as educational tools to protect children from the same issues they might have faced. Additionally, in lieu of racism education, narratives of family racial identity are likely to have be passed on, giving Simba, Four and Bob material to base their personal identity on. As all three of them strongly represented and identified with the racial side of themselves that connected to their parent's historical oppression, it seems likely that the narratives played a large part in identity formation. 


\section{Parental Ability to Deal with Racism}

While it is not a particularly surprising result, it is important to note that the majority of racism narratives, both preparatory and historical, came from within families. While most participants mentioned that their knowledge of race was garnished with information gained from classroom settings, personal and familial connections with race appeared to come from family communication.

In families where one parent was a person of color and the other was EuroAmerican, the parent of color was the one who both had racism stories as well as took the role in educating children on how to deal with racism. Perhaps the only exception to this within the data occurred in Ashley's parents interracial marriage (see: Figure 2), where her Euro-American mother faced racist commentary for being married to a Black man, both from the public and members in her own family. In Ashley's mother's case, inner family racism from her father caused her to break away from that family identity and build her own mixed race family identity based on choices she made about her personal identity. However, despite of this, some of her racial narratives and racial understanding appeared to remain constructed in Euro-American culture. Ashley explained, "My mom always says she really doesn't, she says she doesn't see race or anything" (see: Interview 2, Lines 44-45). While Ashley's mother was privy to narratives concerning race, her own experience with racism was deeply dependent on her choice to marry interracially and did not come from her own familial narrative inheritance. Because of this, most of Ashley's constructions of Black identity came from her father's narratives of lived experiences. 
In a participant named Jacky's family, Jacky's Korean mother was the designated parent who talked both about heritage and about racism, having experienced what it means to look Korean in U.S. American society and live in Korean culture. While Jacky identified as both half-White and half-Korean she strongly held onto Korean culture. There were no reported narratives about race and heritage that came from her father, except for a mention of French lineage from before her father was adopted.

Half-Black half-White J-money could remember his father identifying himself as a Black man, but reported that his mother never called herself a White woman. This is possibly due to the smaller likelihood of needing to claim or defend characteristics that make an individual part of a dominant group. Just as Ashley's mother had the choice not to see color, J-money's mother also was most likely not put in a position where her race was contested or questioned in social settings.

Within this section of the data, the different cultural lived experiences of racial groups becomes obvious, as often, the Euro-American parent often seemed to have little to say on race or racism. In one particularly chilling account, a single Euro-American mother raising her half-Japanese son Jokaio did not have the conversations that mixedrace children raised with parents of color present appeared to have in the data. The participant was one of two people of color at his school, and the other child of color was put into a coma by racist violence shortly after Jokaio left the school. 
Figure 7 - Interview 10, Lines 218-248

Jokaio: Long story short we moved to Idaho and there are like two schools in the rural school in the more city school or town school, and I went to the rural school first and there were basically children of white supremacist at that school, and there was myself, and an African-American kid in 5th grade, and then all you know, white kids most of the kids were pretty cool in school but they were like about 10 of them there's a good old mob and they were trying to beat us up and it kind of escalated until I got myself expelled.

Interviewer: What happened with that?

Jokaio: They circled around me and they were pretty much preparing to beat the shit out of you and I believed them and so I guess I did kind of associate with the Japanese thing and I surprised them a little bit so I just chose one of them you know how it goes there's like the taunting, the talking, the teasing, and all that stuff.

Interviewer: What did they tease you about?

Jokaio: Oh they thought I was Chinese they're like 'Chinese queer.' I was like no I'm not. I never told them I was Japanese.

Interviewer: So you surprised them.

Jokaio: Yeah. So I also grew up doing aikido. So I understood the concept of using someone else's aggression and stuff. So I just walked up to one of them I was scared and pissed off, instead of staying in the middle of the group trying to get away because they kind of lured me. I just went to one of them and I pushed him and then when he pushed me back I did a back roll and threw him overhead and smashed his head on the ground bloody and I came up with him and I had locked him and I told him I'd kill him if they got any closer.

Interviewer: And that's what got you expelled?

Jokaio: Yeah.

Interviewer: What did your mom say about that?

Jokaio: She didn't say anything, just transferred me and then they put the black kid in a coma for two months. 
Jokaio's story puts a frame on the difficulty that many Euro-American parents face in narratively guiding their multiracial children through realities they have never experienced, and coming to terms with their child having a very different personal identity than either their own personal identity or in Jokaio's case, the family identity. While most of the participants were raised with at least one parent of color in the household, Jokaio's mother likely had little preparation from her own life and stories for what her multiracial perceivably Asian son might face in a small-town predominantly White environment. While Jokaio reported her efforts in encouraging his participation in Japanese culture, she had little to no narrative inheritance to give Jokaio concerning racism.

Instances like these raise questions about how incongruent narratives between generations who identify as different racial identities may occur, and how regardless of personal racial identification, physical appearance is often how non-family society members force multiracial kids into a relational identity that may be incongruent with their current personal identity (Jung \& Hecht, 2004). Additionally, Jokaio's narrative shows the power of narratives received in society. Somers (1994) argued that part of coming into personal identity is situating ourselves in social narratives, and that cultural meta-narratives are often what guide this understanding. Even though Jokaio had not received racial narratives from a Japanese parent, interactions in society firmly positioned him as something other than Euro-American, and therefore a minority. In instances such as these, the presence of narratives supporting all sides of an individual's personal identity appears relatively important for both identity development and ability to deal 
with racism. While multiracial children are likely to be instructed on their racial positionality from societal narratives, those who received race messages at home appeared more secure in their personal identity, family identity, and ability to handle racism effectively. 


\section{Cultural Stories}

The second most common theme that directly connected to racial identity was the prevalence of narratives based around culture. Within this theme, a strong sub-theme that arose was 'hardship narratives', or narratives about hardship and overcoming hardship, especially in terms of poverty, immigration, wartime and negative family legacies. The second sub-theme was 'cultural pride' talk. Both of these relied heavily on stories of previous generations and memories of ancestors, which fell in line with Goodall's (2005) conceptualization of narrative inheritance. However, some of the narratives shared included stories about events that had occurred within the lifetime of participants, and were still in the process of being reinforced and performed as an aspect of family culture. Langellier \& Peterson (2004) remarked that most family stories are not canned sequences but rather a family's way of making sense of the world around them, as seen in the narratives recalled about both past and present. This was seen in the production and reproduction of racial identity through reported family narratives.

Narratives about cultural pride and hardship connected to race and culture seemed to be firmly positioned as an important part of family identity sharing, and participants who reported having a large narrative inheritance concerning race also reported identifying more closely with the races the narratives involved. Somers (1994) framed narrative identity as something that is actively done by way of communication, so the process of family members telling these narratives was a way of performing their personal identity and adding it to the family identity. Additionally, the act of participants sharing the racial narratives they remembered and taking part in communicating about 
was a way of them performing their personal racial identity. The focus on large and weighty topics like culture and hardship is important to note, as they serve as an example of what Somers (1994) called meta-narratives, or the narratives that connect people to a larger cultural story. It is possible that the act of enacting narratives like these helps to position both family identity and personal identity in something bigger than just the family unit, and a more dominant racial connective force than that which is available in mixed race families.

\section{Hardship and Overcoming Hardship Stories}

Many participants had parents who had moved from a home country to be in America, which was evident in the wealth of narratives that parents and grandparents had about other countries and other times. Additionally, the narratives did not explicitly mention race but as a byproduct were related directly to racial and cultural differences. While most participants did not mention stories outside of racism narratives that used the word 'race', the concept was still implicit in the reported differences of being brought up by one or two parents who had a different lived cultural experience than they did.

In American-Mexican and Chinese L2R2's account of his mother growing up in Mexico, the narratives that emerged were predominant were class-based, and concerned themselves with poverty and the dangers of poverty. 
Figure 8 - Interview 11, Lines 311-318

L2R2: Like, she'd always tell me accidents that would happen on the farm, like, when they bring in manure, she'd step on something, or when she's baling hay, she cut herself and there's no hospitals anywhere... She would talk about infectious wounds when she was a kid, it was really hard and scary, there's no hospitals, there's only kids and so every time she'd start making me feel like a piece of shit, I just remember where she came from.

It is possible that stories of poverty and experiences in Mexico helped L2R2's mother to express her membership in a larger cultural experience, such as the Mexican immigrant narrative. Even though race is not explicitly mentioned in this story, L2R2's mother's experiences are unique to a certain place and culture associated with that place. When hearing these narratives, L2R2 was forced to share perspectives with his mother and empathize with the hardship tales shared by many Mexican-American families that most certainly affected his family identity and conceptualization of where his family came from.

Three participants had inherited narratives about wartime, though with varying degrees of what was highlighted in the stories. Jacky's Korean mother told stories about growing up in Korea during wartime, as well as relatives in Korea who were still struggling. While these narratives were perceivably more political than racial, they related to specific happenings in participants' country of racial descent, and still informed them with cultural knowledge. 
Figure 9 - Interview 9, Lines 84-92

Jacky: Yeah. My grandpa was kind of pretty well off in North Korea actually. Their house he grew up in is actually still in North Korea but just taken over by the government because it's actually nice but he used to live in a cave for a month because they were going to force him to join the military, North Korea military.

So his family had to hide him in a month in a cave while my grandma went across the river wherever they had to go to get out and then he had to follow after once he got word that it was safe. Yeah. They just want to force him into their government and politics. So that's why they left.

Jacky also remembered hearing about the current conditions in Korea, and the relative poverty and oppression that her extended family lives in. Within this, the acknowledgement of class-based differences between personal identity and the familial identity are present, whereby many of the participants held onto narratives their family had of lesser privilege, yet most likely did not identify themselves as such. Additionally, none of the participants who spoke of war in one of their parent's home countries had direct experience with war. This kind of narrative inheritance was found to relate to the concept of post-memory as written about by Hirsch (1998, as cited by McNay, 2009). Hirsch (1998) argued that younger family members could be dominated by traumatic events if they were not openly communicated about. This seemed to be reflected by participants who received hardship stories as part of their narrative inheritance seemed relatively well acclimated to the stories, and able to integrate them into their personal racial identity.

Even without the class-based identification, these narratives positioned the family identity as a storyline imbedded in a larger historical-cultural narrative. Because of this, 
participants were given a perceivable sense of membership in that cultural narrative by enacting that narrative and allowing it to present itself in their personal identities.

Figure 10 - Interview 9, Lines 135-147

Jacky: ...I remember once my grandma went to... after they escaped they all moved back to the states and my grandma went to North Korea again to go visit and um, she told me what they do is when you go visit someone in North Korea you have to tell the government who you're visiting and the government will go to that person's house and they'll fix it up really nice.

And like, they actually give them food and make it look like they're really happy there and everything. So her family would keep begging her to come visit and people start fighting over when who'd she'd visit and everything because then you actually get food and you get nice things.

So she felt really uncomfortable and it really broke her heart. These are family and she wants to see them but it hurts too to know it's that bad there for them. Yeah it's pretty crazy.

Jacky's narrative demonstrated how she had held on to this narrative and engaged in perspective sharing and empathy with her Korean family's situation, contributing to her understanding of her family's history, race, and culture and allowing her to carry the narrative with her as part of her personal identity, situating where she came from.

Half-Vietnamese half-Chinese DJ Too Real had been given a narrative about a wartime suicide of her grandparents, though it came from a Chinese cousin as her mother had purposefully not told the story, saying it was not important for the new generation to dwell on negative subjects. DJ Too Real's mother's rejection of the narrative of the grandparents reflected the need to disassociate the narrative with the family identity 
(Thompson, Kellas, Soliz, Epp, \& Schrodt, 2009), and keep it from extending into their family legacy, and her children's identity formation.

Figure 11 - Interview 4, Lines 62-69

DJ Too Real: ... So there's that story about like, apparently my mom's dad, my grandpa he was like, the general of this southeastern town in China and also apparently my great grandpa and grandma committed suicide together in like, around like, World War IIish, 1930s, 1940s or something because during that time I think it was Japan had invaded China and they were arresting people and everything and they ended up in this prison cell or something so they just committed suicide together. So that was really shocking that I didn't know about that before.

Despite her mother's objections, DJ Too Real received the narrative from another familial source, so that regardless of her mother's exclusion of it from their family or communal identity (Hecht, 2004), it had potential to play a role in DJ Too Real's formation of her personal identity and concept of her racial history. Additionally, DJ Too Real reported being shocked by the story, a reaction that reflected Hirsch's (1998, as cited by McNay, 2009) concept of post-memory. Because the traumatic event was part of the family identity whether DJ Too Real's mother wanted it to be or not, DJ Too Real felt personal connection to the story and integrated it as part of her narrative inheritance of her Chinese side, very few narratives given to her about her Vietnamese side.

Lastly, the subject of gangs, and getting out of gangs arose as an overcoming hardship narrative. Three participants mentioned gangs while two reported narratives that directly connected their parents to them. As gangs are often racially based in nature, it would seem appropriate that at least some participants would have had experiences with them or narratives of gangs within their families. Gang membership is often used as a 
way of asserting racial and cultural solidarity and of performing a communal identity, and narratives of affiliation were likely received with an understanding of their racial implications.

When Simba was asked what he knew about his mother, he reported remembering his mother talking about being in gangs growing up, and getting out of those situations. Simba's method of inheriting these narratives however, was by way of overhearing her speak to others, not necessarily by direct and purposeful narrative sharing. This is important to note as it is evidence that not all inherited narratives are given with purpose, yet children may still choose to make those narratives part of their identity.

Figure 12 - Interview 1, Lines 228-234

Simba: About her growing up? Not a whole lot. I knew she went through a lot of things I went through trying to find herself as being... in the culture of being Hispanic and native and being pulled in by the Hispanic thing and doing all the whole... she was in the gang Hispanic thing growing up and doing that as a teenager and then realizing as she got older that da da da daaa.

Interviewer: How did you feel when she shared these things with you?

Simba: She never really shared them with me. I kind of just observed...a lot of communication that she had when she got older. She got into the church thing for a little bit and had some church friends over and talked about it and she would show photo albums and this is who I was and this is where I came from. That's who I used to be.

Simba spent part of his youth in Hispanic gangs and had 'Brown pride' tattooed across his forearm as a testament to previous membership and racial pride. While he reported regretting both the tattoo and the involvement with gangs, it is possible that his Hispanic identity at the time was reinforced by stories of this mother's that related to his 
own experiences, and that he chose to held onto parts of his mother's narratives that related to his own personal narratives.

J-money also knew of his father's past relationship in gangs, and similarly to Simba, was not always given explicit details but discovered some narratives through inference.

Figure 13 - Interview 8, Lines 59-75

Interviewer: Where did he grow up?

J Money: Chicago, South Side, very very very... probably one of the roughest parts of the United States, yeah, like as hood as you can get. That's what the South Side Chicago is like, yeah.

Interviewer: What else did he tell you about growing up?

J Money: Well, he was in gangs. He was in the GDs, no, the BGDs, [Laughter] the Black Gangster Disciples - is what the acronym means. So he grew up in a gang and it's just a part of growing up in a place like that, you don't really have any outlets to... you're a product of your environment so if you're hanging around... if all you see is thugs you're going to grow up where you're just going to become the same thing that you surround yourself with.

It's interesting, I remember when I was 8 we were driving to car and I asked if he ever killed anybody and he just paused for a long time and just said "Son there are some things that you don't need to know." That's like all he said and even though I was eight, I kind of understood what he was telling me was yes, but he doesn't want to say that.

J-money's memory is another example of a child putting together pieces of their parent's narrative to make sense of their story, whether or not the parent wished to share that particular narrative. In both cases Simba and J-money's recall and report of those 
narratives is evidence that they took their parents' gang narratives as part of their history and familial identity, and in Simba's case probably his personal identity.

In both cases, the parents had removed themselves from gang situations, Simba's mother finding Christianity and J-money's father committing himself to Rastafarianism in the aftermath. Just as DJ Too Real's mother did not necessarily wish to pass on all the details of her family's hardship, Simba and J-money's parents appeared to also quiet that previous aspect of their lives away from their family identity. However, in other participants' cases, hardship narratives served as a constructive tool in positioning their family and themselves in a historical meta-narrative, and allowed them ownership of a racial identity due to their ability to perform narratives concerning it.

\section{Cultural Pride}

The other majority of narratives centered on cultural pride and family legacy. While these are arguably directly connected with narratives of hardship, they were more ubiquitous and erred on the positive side of highlighting accomplishments and connecting back in with the parent's traditions and cultural knowledge bases. All of the participants had at least one narrative that was coded under 'cultural pride', though the range of how they were presented was quite wide, coming by way of familial success stories, cultural education, and scripts on being proud of heritage.

The first of these cultural pride categories was narratives comprised of remembrance and acknowledgement of cultural difference and racial background, as well as pride dialogues of 'remember who you are'. Narratives like this were seen to be especially important as even in participants who identified more as White than as mixed 
or as a person of color, some of those narratives were still remembered and reported, thereby becoming part of their narrative identity.

Jacky and her Korean mother often kept up with news events of Korea, and her mother chose to raise her in Little Korea, despite her Euro-American father, reinforcing Jacky's integration into Korean culture by placing her around a wealth of cultural narratives coming from outside the family.

While Jokaio's mother identified as White and seemed to avoid racism talk, Jokaio still accounted for her efforts in taking him to play with other part-Japanese children and trying to educate him in Japanese culture, sometimes inaccurately, as told in a particularly humorous memory of Jokaio’s.

\section{Figure 14 - Interview 10, Lines 60-76}

Jokaio: Yeah. She tried a lot to give me exposure to Japanese culture but she has no exposure to it herself. So it's mostly trying to connect me to other people. Oh we're going to so and so's house for dinner. The mother's Japanese and she's going to make us Japanese food or something. You should try to talk to her... or you know.

Interviewer: What did she tell you or some of the things she did that told you about being Japanese?

Jokaio: I can't remember. I didn't think she told me. She, again, trying to expose me to Japanese culture, she got a lot of things kind of wrong. Like when I was a kid playing with legos or whatever, she always set up these little bowls of little dried fish, that big. It turns out that you don't really eat those like that in Japan. There's different ones that people do sometimes. They'd be like little dried fish that they will eat but these were for making soup stock.

Interviewer: And you ate them?

Jokaio: Yeah lots of them. You can get giant bags of them because it's for soup stock. It was a pretty main staple and snack for me as a little kid. 
However inaccurately Jokaio's mother enacted Japanese culture for Jokaio, he was still given the ownership and knowledge of some cultural narratives. The ending to Jokaio's story involved a narrative of his arrival in Japan to meet his Japanese father, who upon watching his consumption of bouillon stock, quickly pointed Jokaio's mistake. By that point in time however, Jokaio's choice to travel to Japan, learn Japanese and live with his father probably built a stronger cultural narrative than the ingestion of soup stock as a snack.

Cultural pride narratives also came by way of highlighting cultural characteristics associated with the parent's race, L2R2's mother expressed that she wished he were a bit more Mexican, and Ina's mother lamented over the differences between American teenagers and the family-based Latino culture that is prevalent in Mexico. In both of these narratives, parental cultural pride is recognizable, as well as the difference between the cultural identity they wished to maintain within their family and it's juxtaposition with their child's enactment of personal identity.

Most of the narratives had something to do with racial solidity, and acceptance of self, such as in Half-Guatemalan half -White Zach's account. While Zach identified personally as White, he came from Guatemalan lineage and experienced some racial confusion and racism similar to Bob (see: Figure 4) due to ambiguous racial appearance. However, he was given a narrative that helped him counteract racism while simultaneously affirming the racial pride members of his family held, whether or not he chose to identify similarly to them. Zach's case was interesting in that while he was raised in what he explained as White culture with a White father, and identified as White, 
he still carried with him the racial narratives of his mother and enacted them, but chose not to identify in accordance to them. This may have been due to being raised in a dominantly Euro-American culture as well as having a sister who looked physically Euro-American and also identified as White.

Figure 15 - Interview 12, Lines 207-211

Zach: I think most of the time she's been trying to influence me to become empowered by that and to say you know that your mom, and I and your grandma are full Guatemalan and that's very much a quarter of you? Sure they call you that. You're tan for a reason. I think she always tried to be... not inspired, but always try to teach me and coach me.

J-money called himself "Mulatto, black and white... a hybrid. Jamaican and Swedish" (see: Interview 8, Lines 28-29), was given pride narratives from both his mother in relation to being multiracial, and his father in relation to being Black. J-money was very secure in his identity as a Black man and seemed to enact both his identity as a person of mixed race and his identity as a Black man simultaneously, saying that he thought it would be strange if he identified as anything other than a Black man as that is what he appeared as. Because J-money inherited strong narratives concerning both Blackness and being mixed race, he felt comfortable identifying as either depending on the context.

Figure 16 - Interview 8, Lines 40-43

J-money: Yeah. My mom would say like "Baby you got the best of both worlds." [Laughter] That's pretty much it. I mean my dad would always... he would always tell me that I was Black. He was very, very um, passionate about making sure that I understood that I was a Black man in this society. 
Both J-money's and Zach's cases were also examples of the fluidity of relational identities, whereby they acknowledged their different races and were given racial pride narratives, yet still chose to self-identify by a singular race on a regular basis. For Jmoney, this was due to his physical appearance and the perception that it is what was expected of him from his father, and for Zach it was based on the dominant cultural narrative he was raised around.

An interesting observation to note was that all three of the participants who identified themselves as coming from African American lineage were instilled with Black pride narratives. Along with J-money's account of his father, Ashley described her father and his family as being extremely prideful and growing up in a strong Black community, and Four recounted his mother's insistence that his two adopted bi-racial sisters only play with Black Barbie dolls. All of these participants were forthright in enacting Blackness as a large part of their identity. It is possible that this came from a cultural meta-narrative of Black pride that is found in the United States. Because the context the participants grew up in was shaped by Black pride as an aspect of family identity as well as a larger cultural narrative of the Black experience, it would seem that adopting Blackness in their personal identity would be important.

Two participants who identified as part-Mexican seemed to shy away more from their cultural heritage in their youth, despite their parents' identification as such, both of them expressing an inner-racist sentiment. L2R2's journey to cultural pride happened later in life with the help of his sister, while Simba found a way to counter it by asserting his other races. 
Figure 17 - Interview 11, Lines 7-12

L2R2: No especially growing up, like, I definitely just - a lot of prejudice, in kids especially. So, I just always call myself White and then actually, yeah, really, I don't remember what it was, I think my sister worked for the YWCA that made me realize like, whoa, there's some definitely inner racism in me and I was like, I don't like that shit. So yeah, I literally started to identify myself as Mexican.

Figure 18 - Interview 1, Lines 215-219

Simba: I remember being ashamed growing of being Hispanic because nobody like... oh you're Mexican like yeah so what? And I was like what do you mean? I'm not just... that's when I started saying “Okay. I'm not just Mexican. Hey I'm actually Puerto Rican, Filipino and native brah so chill out.

It is possible that another cultural meta-narrative was at play in both participants' accounts of racial avoidance or shame. Just as Black pride is a powerful cultural narrative in the United States, the Mexican American experience is likely to reflect another narrative, one that possibly has less prideful roots due to politicized media stereotyping of immigration. Jimiez's (2004) work with multiethnic Mexican Americans found that many mixed-race Mexican-American individuals used their multiple identities for social advantage. While Simba identified as Hispanic around his Hispanic family in concordance with his family identity, he brought up his other roots when enacting his personal identity in certain social situations, using the fluidity of identity to his advantage, avoiding the possible negative connotations of a larger cultural narrative he had no control over. 


\section{Family Narrative Construction}

RQ2 asked what factors are potentially related to the process of inheriting narratives. Results presented several ways that different family constructions may have played a part in determining which narratives were received by children, and perceivably taken into account as they formed their personal racial identities.

Within the results for the second research question, several factors arose as seemingly connected to the construction of family narratives and the receiving process of narratives inheritances. The largest of these themes was 'divergent family structures' (including divorce, separation, adoption, or social discord), 'who talks', or who held most of the talking power or narrative dominance within a family, and 'language barriers' within families.

\section{Divergent Family Structures}

In multiracial families, several factors appeared to affect the flow of narratives from older generations to younger generations, but the most inhibitory factor reported concerning communication was inter-family discord or separation, which came up in almost all of the participant interviews. Koenig Kellas's (2006) found that processes of family storytelling are often affected by other family relational processes, and multiracial participant's accounts of family discord or divergence seemed to reflect this.

Glenn who said he was half Puerto-Rican and half-White but identified as White said that because his father didn't get along with his Puerto Rican relatives, and because Glenn in turn didn't get along with his father, he had relatively few narratives given to 
him about being Puerto-Rican, and relied more heavily on family stories coming from his Euro-American mother's side.

L2R2 also reported having social discord with his mother for a large period of his life, and did not identify as Mexican during his youth, partially due to his lack of positive communication with his mother and acceptance or inquiry of her narratives. L2R2 eventually began to enact his Mexican side as part of his personal identity after talking about race with his sister as a teenager, and being given a racial pride script from her.

Ashley's mother's family was inherently racist at the beginning of her marriage to Ashley's Black father, which caused a rift wherein Ashley said she did not talk about her Italian heritage much simply because she didn't talk about her family much. It is possible that Ashley's mother strayed away from her cultural narratives because she was attempting to move away from a negative legacy of racism within her family. This resulted in Ashley inheriting more narratives concerning Black racial identity than narratives concerning Italian or White identity. It is also possible in this instance that even if Ashley's mother was close to her extended family, Ashley still may not have received any specific Euro-American narratives

When DJ Too Real was asked about how her family talked about heritage, she explained that her mother was both fairly quiet, as well as not in a place of harmony with her grandfather, resulting in her predominant heritage stories coming from an uncle. Additionally, DJ Too Real identified more with her Chinese side due to her Vietnamese father's lack of shared narratives and adoption of the Chinese language. 
Figure 19 - Interview 4, Lines 178-187

DJ Too Real: I feel like maybe it's just like my mom, because my dad doesn't really say much in the family or whatever. My mom pretty much controls the relationship in the family and my mom's just that kind of person who doesn't like to talk about personal things I guess.

So it's really hard to talk to her about feelings about that kind of stuff so I feel like when it comes to family history because I know she's not too close with her dad anymore. I feel like that's part of the reason why she doesn't talk about because I'm pretty sure her dad's a really pretty big part of the family history which is why my mom's cousin constantly brings them up whenever he comes over or whatever.

Interviewer: So, do they have a problem or a fall out?

DJ Too Real: Well after my mom's mom died my mom's dad remarried and it was shortly after she died and so my mom had an issue with that. I don't think she really ever got pass it. So I think that's why they're not on speaking terms or anything. So I feel like that's why she doesn't want to talk about it.

Another way in which narrative inheritance was affected came with divorce and parental separation. Simba was raised by a few different father figures and a stint in foster homes that may have contributed to his racial uncertainty and fluidity, while L2R2 both disliked his father and was not raised with him. This kept L2R2 from learning about his father's Chinese side throughout his youth. Ina also had the experience of being raised with her Mexican mother and not finding out about her father's Lebanese lineage until she was a teenager, though dealt with people constantly telling her she looked like she was other races besides Mexican. In these instances, it becomes clear that separation from a parent impedes the racial narratives a child is able to receive about some sides of themselves, and can result in racial confusion or a feeling of racial displacement. 
J-money's father passed away when he was 18, and most of J-money's family narratives came from his mother or his father's mother, who still lives in Chicago where his father grew up. While J-money had a strong sense of his racial identity from communication with his father before he passed away, he still reported less racial narratives than other participants who had parents that were still living.

Lastly, Jacky's father was adopted from France, and while Jacky identified as half-White and specifically half-French, she reported that she did not have a good knowledge base of French culture. While Jacky did not identify culturally as French, she did report that she added to her identity for its exotic-sounding qualities, something that reflected Asultunay's (1998) assertion of the exoticism associated with mixed race. In this context, Jacky's enacted identity was apparent, whereby her awareness of a societal advantage was used to shift her identity depending on the context.

Zach's stepfather who raised him was also adopted, so had little racial history to offer, and his biological father was not in contact with him. Therefore, racially or otherwise, Zach lacked any narratives relating to his biological father yet still identified as White like his stepfather. This is a reminder of the relatively minimal role of genetics in personal identity, as Zach's Euro-American identity was largely learned from growing up with his stepfather and from interactions in society.

\section{Who Talks}

Another common theme that relates to the construction of narratives was who held talking power within the family, or who was simply perceived as more verbose. This is interrelated with family divergence as it was found that parents who didn't get along 
with their families appeared to talk about their family history less, however, it is also appeared to be based on structures of power within a given household as well as personality type. It is possible that in households with one parent of color and one EuroAmerican parent, the parent of color might give the most race-based narratives based on their lived experience of being a minority. However, in households where both parents were considered people of color, the narratives shared could very possibly come down to family dynamics.

L2R2 received most of his racial narratives from his sister, as she was the person he had the best relationship with, and Simba, Jacky, Ina, and Zach, all experienced a heavier dialogue flow from their mothers as opposed to their fathers, both from proximity and from their mother's willingness to talk more. This reflected Frabutt, Walker, \& MacKinnon-Lewis' (2002) findings showed educated mothers had a higher rate of involvement in racial socialization of their children than other groups. It is unclear from the data whether this has to do with gender norms or family structures, but it is relevant to note in the case of mixed race families due to its possible role in possible disproportionate narrative sharing.

Heritage talk not only came from inside the immediate family, but also for a number of participants, from extended family. Jokaio remembered inaccurately thinking his mother was Irish until an uncle at a family gathering told them they were Italian. DJ Too Real also reported receiving a large part of her narrative inheritance from her Uncle. Simba and Glenn both received most of their knowledge of their Native American lineage from their grandmothers, though Glenn doubted the authenticity of his 
grandmother's narratives, and Zach also remembers his grandmother having a predominant role in educating him about his Guatemalan side.

Figure 20 - Interview 6, Lines 67-71

Glenn: Well she told me a little bit about how the Cherokee because I feel like she is definitely not very much Cherokee but she feels like that's such a big thing. So she like, really clings on to it and she tells stories and dresses up and stuff even though it's not at all really a part of her ethnicity all so much.

Whether narratives from extended family are accepted as part of a personal identity (as in the case of Simba) or rejected as seen in Glenn's story, it is clear that extended family plays a large role in identity formation as well, as they offer a wealth of narratives that are possibly different from those the immediate family has enacted. Additionally, it is apparent that the more talkative parents have a better chance of passing on their own racial narratives.

\section{Language}

Language also emerged as a major factor in the construction and disbursement of family narratives. Most of the participants had at least one language other than English spoken in their families, but had varying degrees of competency in the languages themselves. Language served as a barrier in some cases and a connector in others, as well as a way in which race-based culture was reinforced. Furthermore, language appeared to play a large role in personal identity as children who could not speak the language of their family members had difficulty inheriting narratives from them.

Jacky had trouble speaking to her Korean grandmother with her elementary Korean and so received most of her narratives about her grandmother through her mother, 
who also served as a translator when Jacky wished to write to her grandmother. Jokaio went to Japan after connecting with his Japanese father to better learn the language so that he could communicate with his family members more than when he first met them. Glenn also experienced a barrier with his Puerto Rican family upon visiting them for the first time in Puerto Rico.

Figure 21 - Interview 6, Lines 166-173

Glenn: She said that if I ever come back to Puerto Rico and I don't know Spanish then she's not going to cook for me. So she really wants me to learn the language and that's a huge thing with the culture in the family is like, knowing how to speak Spanish or at least Spanglish because my dad speaks Spanglish all the time but I've never... he never taught me unfortunately but she's really big on that. So that's one of the reason why I really want to learn Spanish just because I feel it will really connect with that part of my family and stuff.

In Glenn's narrative, he showed a desire to adopt more of a Puerto Rican identity than the one he has currently, or simply to be able to partake in a Puerto Rican family identity when around those members, but had difficulty due to his inability to communicate with the people he wanted to be closer with.

L2R2 also remarked on the difficulty he had connecting with the Hispanic side of not only his family but also himself, due to his inability to speak Spanish. As L2R2 grew up in a community with a large Hispanic population, his inability to partake in narrative sharing both with his community and with his family left him unsure of where he racially belonged. Ina grew up speaking Spanish in her family over Lebanese, and reported related to her Mexican side heavily, spending time with her Spanish speaking family often both at home and during visits to Mexico. Simba reported identifying more as 
Mexican than with his Filipino and Native American sides partially due to spending time in a completely Spanish-speaking household. When asked if his mother talked to him about race, he responded with a story of his childhood household dynamics.

\section{Figure 22 - Interview 1, Lines 160-166}

Simba: I think she tried to when I was younger but I didn't really... I was just... she was really... I was just a youth, I wasn't really interested. I mean because I was full blown Hispanic growing up. I mean I was like my mom had stuff in the house like I was Hispanic and when I wasn't there when I was thrown into my real dad's house. I was full blown Hispanic.

There was no English that was spoken there. To go from that and then to go home and then after school go to my grandma's. My grandmas Native I was Mexican...

DJ Too Real also commented that she identified more with her Chinese side than her Vietnamese side saying, "I feel like because both of my parents speak Chinese we always just went with the Chinese culture more like anything else" (see: Interview 4, Lines 124-136). Not only was her Vietnamese father a less dominant communicator in comparison to her Chinese mother, but Chinese was the language spoken in their home that may have played a role in connecting her to a larger metanarrative concerning Chinese culture.

In many of these accounts of language, a pivotal visit to a parents' land of origin is somehow incorporated. Many of the participants did not realize their own language inadequacy until they were faced with a situation where they were expected to speak the language of their heritage with extended family members and could not perform. Language aside, the visit to see extended family in a location of racial heritage seemed to be an important milestone in many participants' identity formation, and eight of the 
participants had narratives about visiting where one of their parents had grown up, or their extended family. This is possibly due to the actualization of what their family members had told them about where they came from, as well as the ability to ground narratives in a sense of place. 
Conclusion

In the collection and analysis of data, narrative inheritances proved to be an informative and effective method through which to study racial identities in multiracial families. The storied resource perspective of narrative identity (Somers, 1994, Smith \& Sparkes, 2008) proved to be a useful theory to guide analysis of the role of narrative in construction of family and personal racial identity, as it showed how significant parts of participants' personal identities were formed based on a plethora of narratives from within their family, society, as well as from enactment of their own narratives.

The method of semi-structured interviews reflected that identity sense-making came from both the stories participants remembered and told about their families as well as the act of conversing about those narratives with the interviewer. Field notes recorded after interview completions showed catharsis talk, whereby participants reflected on how they hadn't considered some of the things they had spoken about during the interview previously in their lives, or continued their train of thought about how they wished they "knew more about the "part missing"", or wished they "could remember more family stories". The storied resource perspective was helpful in analyzing the data in that it recognizes narratives that draw on experiences, other's stories, and cultural knowledge cannot necessarily be disconnected from a person's identity, so that both the stories shared and the act of sharing perceivably contributed to personal identity formation and helped to reflect how participants situate themselves in comparison to their family identity. 
RQ1 asked what kinds of narrative inheritance people in multiracial families receive about race. Themes that arose from the data were 'racism narratives', 'hardship narratives', and 'cultural pride' narratives. All of these themes pointed to the importance of Somers's (1994) concept of cultural meta-narratives. Cultural meta-narratives are large-scale narratives that are often based in history, and they appeared to help participants locate their personal racial identity in the scope of not only their family identity, but their racial group(s)' identity as a whole. Racial groups' experiences with racism, war, immigration, oppression, poverty and enactment of culture represent a larger community and participants' knowledge of narratives that related to that community appeared to help them feel part of it, and identify as part of it.

Racism narratives were important in that in many cases. They not only tapped into a meta-narrative of oppression that was part of the family identity, but they also prepared participants for the more unsavory aspects of existing in a racialized society. Racism narratives also helped give participants context and understanding for both what their parents had experienced, as well as what they might or already had faced in certain social settings. Many participants' first memory of racism came from a school setting, and those who had parents who could explain and share stories about their own experiences appeared more at home and confident in their personal identity as a mixed race person or as a person of color, as seen in Bob's or Four's interviews. In Jokaio's case where racism narratives were not present, there seemed to be a sharp difference in personal identity from the family identity constructed by his mother, as her lived experience and narratives could not account for what he faced as a marked body. 
Another aspect to note in this is the relative quietness of many multiracial children's Euro-American stories in connection to race, which connects directly to Whiteness and it's oftentimes appearance as culture-less (Warren, 2007). Because 'White' or 'American' storylines are ones that are often so well-known they are forgotten as stories and exist simply as 'facts', there may be important dialogues that go missing in families that could construct Whiteness to be a culture attached to various races in itself. Additionally, it is possible that a level of guilt exists in identification with White culture, which keeps it from being talked about as openly. When a person of Euro-American descent is asked what races they are, they often give a list of European nations without much connection to those specific cultures. Multiracial children could face a similar issue with an extinction of minority cultural stories in the future, once many of the racial metanarratives no longer need to be based on racism, hardship, and methods to deal with both. This loss of cultural heritage could be detrimental to keeping alive the narratives of cultural ancestors, and encouraging and understanding of racial history that helps connect people in with larger meta-narratives.

The multitude of cultural pride narratives received by multiracial children served as an important finding as well. Cultural narratives can give a sense of belonging to parts of a multiracial person's identity and tie the individual back into a meta-narrative of their family or racial group's experiences, which can be more powerful than that of their own personal lived experiences. While Jacky's mother encouraged her participation in the Korean church and told her stories of her ancestors and their lives, Ashley's father highlighted the importance of education and held onto their family legacy of enacting 
highly educated upper-middle class upbringings. Cultural pride narratives were seen to be not only in reference to the race aspect of culture but also attached to aspects of family social culture and the norms it promoted.

Participants like Ina faced difficulties with their racial identities when the parent who came from a certain culture was either absent or did not focus on sharing cultural narratives. When Ina found out her father was of Lebanese roots she began to question him about the culture, wanting to know if he spoke the language, what kinds of foods he used to eat, and if they still had family in Lebanon. Perceivably, this was a way to collect narratives through which to make sense of the neglected part of her personal identity. Participants like Ina who physically appeared to be mixed but were missing cultural narratives that helped situate them as a multiracial person often had confusion and difficulty in formation of personal identity.

The prevalence of hardship narratives was also a relevant finding, as parents either chose to highlight the current or past hardships they had faced, or avoid them due to a myriad of factors such as pride, or attempts to move past negative baggage. Participants who held onto family hardship narratives voiced them most often with what the interviewer perceived as a sense of empathy, whereby even if the stories did not seem to be enacted regularly in the participant's personal identity, their connection to these stories was still evident. As mixed race individuals are often in a position of constantly having people contest their racial identity, it is possible that narratives of hardship associated with their racial group helped ascertain group membership and understanding of historical trauma, and connect them with a more cohesive family identity. Kellas \& 
Trees's (2006) research showed that single integrated stories in families that can be told jointly assist in creating a family identity, and it would seem likely that family stories about big and consequential topics such as war and poverty helped to nurture that.

RQ 2 asked what factors were potentially related to the process of inheriting narratives in multiracial families. Data indicated that 'divergent family structures', 'who talks' and 'language barriers' all played a role in determining what kind of racial narrative inheritance the child was likely to receive.

Participants who had divergent family structures had experienced divorce, separation, adoption or family discord at some point in their families. All of this contributed to the extinction or stifling of one parent's narratives and within that, their racial narrative. In families where the parent didn't get along with their extended family, participants reported a lack of narratives concerning those members or that culture, and in families where the child did not get along amicably with one of their parents, there was also a lack of narratives due to less time spent communicating. Two participants reported having parents who were adopted, and data showed that those parents had few racial narratives. This served as a blockade for narratives relating to the parents' racial background, but did not seem to have negative effect on participants' conceptualization of their personal identity as in both cases their other parent was able to provide strong racial narratives.

The theme of 'who talks' tied in closely with Kellas \&Trees' (2006) findings that family storytelling is dependent on family dynamics. In many participants' cases, there were reports of receiving a larger narrative inheritance from one parent simply because 
that parent was more likely to be talkative, and spend time sharing narratives with them. In families like these, participants tended to align their personal racial identity with the racial identity of the parent who shared the most narratives, as those were the narratives that were more influential in the construction of the family identity.

Many participants also faced the stifling of part of their potential narrative inheritance due to their inability to speak a cultural mother tongue. This resulted in many of them feeling as though they were missing a part of themselves, or being unable to fully enact the identity that was being prescribed to them by the social world around them. Language competency helps to assert group membership, and allows multiracial individuals more access to narratives of one of their racial groups both from within the family and outside of it. Language competency also was shown to allow better connection with extended family and ability to receive narratives with relatives other than parents, which resulted in a wider range of stories included in participants' narrative inheritance. This highlights the possible importance of language education or finding other ways through which to communicate narratives in family, such as Jacky's mother's method of translating letters into Korean between grandmother and granddaughter.

RQ 3 asked how narrative inheritance might relate to reported personal identity, and themes from RQ 1 and RQ 2 guided the results for this. Personal identity expression was found to be dependent on a myriad of societal narratives though heavily dependent on the content of the narrative inheritance received about race and the frequency with which they were received. Participants who were given a wealth of narratives concerning racism, cultural pride, and hardships their specific racial group may have faced were 
more likely to appear to enact seemingly positive racial identities relating to those races. Additionally, they were more likely to relate to their family identity, and draw large parts of their personal racial identity from the racial narratives enacted by their family members. In families where one parent's narrative was silenced due to discord, separation, or lack of lived experience, children reported less knowledge and confidence in the part of their racial identity that reflected that parent's race. In cases where language was an issue, participants who couldn't speak the language of their extended family reported feeling less connected to that racial background with less narratives to support their racial identification.

\section{Direction for Future Research}

A way in which this study could be built upon would be to focus on a specific racial mix and the family narratives inherited in that racial family structure to look for cultural similarities that might occur in one group (i.e. Chinese and Euro-American). In research like this, evidence of specific family dynamics, cultural meta-narratives and racism might be presented in a way that is easier to discern more concrete correlations in.

Future research could also expand on the importance of environment in relation to mixed-race family narratives, both in level of importance as well as types of narratives shared. In many participants' stories, parents' narratives were inquired about after realizing racial difference from growing up in predominantly Euro-American environments. However, it would be relevant to note if mixed-race families existing in an environment with other mixed-race families had a different way of transmitting or receiving narratives and building personal identities. Would racism narratives occur as 
often? Would living in a highly multiracial community promote enactment of personal racial identity or decrease highlighting of cultural differences? Additionally, research could look into the variance of personal identities within a singular family structure, as many of the participants' had siblings who had chosen an identity different than the participant's. This was seen in Glenn's family where his older brother had chosen to identify as Puerto Rican, despite the relatively few family narratives they had about being Puerto Rican.

Future research would also benefit to include class and gender as pertinent aspect of narrative inheritances. In most of the interviews occurring in this study, the mother and grandmother figure held a primary role in the sharing of narratives, especially in the event of cultural pride narratives. In many cultures, women have long been assigned a matriarchal role whereby oral stories are their responsibility to share, however this should be looked at with sensitivity to mixed race family structures, keeping in mind what this study has observed on parents of color sharing more recognizable cultural and racial narratives. This was not seen in participants who were of African American descent. Four's and J-money's fathers were integral in encouraging their sons to be proud Black men, and according to Ashley, Ashley's brother identified very much as a Black man even though Ashley and her sister identified as mixed. Jackson (2006) has theorized the gendered social constructs of Black masculinity in America, and it would be pertinent to look into how this holds up in relation to mixed race identity and narratives coming from male figures. 
Lastly, most of the participants in this study were of middle class standing, and roughly half were currently in college. A follow up study might be to look at the narratives of race that occur in multiracial families of different socio-economic classes and education levels, to see how the handling of such narratives might differ.

Future research would benefit greatly from using multiple methods of inquiry about mixed race identity, and employing data from qualitative studies to help inform quantitative analysis about narratives and mixed race identity. While this study was able to form some categories and themes related to the topic, quantitative data is needed to be able to expand and form generalizations, as well as find causalities.

\section{Moving Forward}

While numerous scholars have worked with the importance of narratives in the production, performance, and maintenance of identity, there has been little scholarship completed on the complexity of multiracial identity in conjunction with overall family identity, and the production of such through the advent of family narratives. In this current era where the number of interracial families is rising rapidly it would seem that racial identity confusion might become less of an issue, however I believe it is because of this very reason it should be studied further. The way that humans of every race have often found identity is through family and other forms of social construction, so the mixing of racial and cultural narratives adds complications to family identity where some stories and connections are highlighted and others lost. Within family storytelling and narratives, there lies a unique platform from which matters can be discussed that ultimately can result in a sense of belonging, a development of confidence in personal 
identity, and an ability to counter much of the contestation and questions that people of mixed race and ambiguous physical features often face. Additionally, family narratives can help both families and individuals feel like they are part of a larger cultural metanarrative, where they can assert pride in the historical narrative of their racial background.

A habit in socialization is to avoid the mentioning of something unless it is a problem or a conflict, as seen in intercultural communication practices usually being about conflict in communication, or queer studies often focusing on problematizations of queerness. This was seen in participant interviews as well, as in most cases, race was not mentioned, affirmed, or involved in storytelling until it became an issue or point of confusion for the child. Joseph et. al (2013) noted the importance of racial education beginning from an early age, and based on this study, I argue that a viable method of racial assimilation and education can come through narrative sharing. Additionally, I argue that as the United States becomes increasingly more mixed race in population, the importance of race narratives is important in preservation of family identities and cultural knowledge. If the act of narrative sharing and recalling narratives about family members helps multiracial people in the formation of identity and sense of belonging, it is vital to cultural diversity and the preservation identity actualization that narratives continue to be told. The loss of many family narratives, especially in multiracial families where the racial identity that is more socially problematized seems to be highlighted is not something that should be ignored. It is very possible that all racial narratives from all 
sides hold are necessary to encourage personal identity cohesion and understanding of family identity.

From this study, it can be surmised that narrative inheritance from family is certainly not the only factor that affects the building of personal identities but is a large one, and that family identity is an amorphous and fluid concept where members can choose what aspects they wish to continue to pass on and which they prefer to leave in past generations. Additionally, not all neglected inheritances are from parental choice, but also are lost through different formations of family structures ranging from absent parents to language barriers between children and their extended family. Still, family narratives are shown to be an integral part of forming personal identity, and deserve more focus in scholarship about multiracial families.

The space between family identity and personal identity was found to be a reaffirmation of society's social construction of race based on physical appearance and need for categorization, as participants were often not forced to build and assert their personal identity until challenged by members outside of the family. Narrative inheritances can help guide and protect children on their journey to building their personal identity, and help families build a cohesive family identity.

Multiracial census identification is numbered along the fasted growing categories of racial identification in the United States, and since 2000, the number of people identifying as more than one race has jumped by 32 percent. (Funderburg, 2013). Numbers are expected to continue rising as immigration policies shift, interracial marriages increase, and birthrates for different racial and ethnic groups change. While 
current census data and predictions can account for how many people report their phenotypic background, it does very little to show how multiracial people actually identify in their daily lives, how they have arrived at that identification, and how they choose to enact it in their lives. The data from this project revealed that multiracial people's self-identifications were often remarkable different from the bloodlines of their parents. For example, Guatemalan and White Zach chose to identify as only White, while Vietnamese and Chinese DJ Too Real chose to identify as Chinese most often.

It is within this gap that the need for social science research is most highlighted. While census data can account for the numbers of certain races present and is employed to make future predictions about mixed race America, it can do little else. Census data cannot look at why, for example, participant J-money identifies more often as Black then as mixed, or why nearly all-Black Four identified as mixed. This is where quantitative surveys like the census would benefit from being based off of qualitative studies such as this one, in order to collect data on mixed race identity with a more multi-dimensional approach. Racial identification has little do with numbers and amount of genetic heritage. It has much more to do with the daily cultural enactments of racial identity, often produced and fueled by the narratives of the people around us. Census data has the power to inform on the potential for multiracial identity and possible presence of multiple racial narratives, but not the social important of multiracial people's individual processes of racial identification.

While this study does attempted to find some commonalities in the identification processes of multiracial individuals, it also recognized that different family structures and 
cultural narratives are likely to lead to very different experiences. Still, some commonalities exist in identity production of multiracial identity due to some of the similar social scripts that are shared in situations of perceived racial ambiguity. Root (1996) list of questions multiracial people are likely to face articulated the similar experiences that many multiracial people face from the outside world. However, it did not look at how inner-family experiences might vary and did not make any claims on similarities of in-family storytelling in relation to race. The wide variety of family structures that are socially accepted in modern day United States offer a range of different experiences and constructions of narratives, especially when combined with multiple races. It is because of this that it becomes important to not only look at the specificities of multiracial identity as a socially constructed process that is likely to change the face of the United States, but also as a process immediately affected by the ability to share narratives in families.

To be of mixed race in today's world is to often exist in a constant rearranging of identity boundaries, based on the environment, the company, and the current stage of individual development. However, families often serve as the first point of social education especially about difficult subjects such as race, and narrative inheritances from family perform an important role in the construction of personal racial identity. 


\section{References}

Asultunay, E. (2004). Toward a multiethnic cartography: Multiracial identity, monoracial cultural logic, and popular culture. In Kwan, S, \& Speirs, K (Eds.). Mixing it up: Multiracial subjects. Austin, TX: University of Texas Press.

Ballard, R. L., \& Ballard, S. J. (2011). From Narrative inheritance to narrative momentum: Past, present, and future stories in an international adoptive family. Journal of Family Communication, 11(2), 69-84. doi:10.1080/15267431.2011.554618

Baylis, F. (2003). Black as me: Narrative identity. Developing World Bioethics, 3, 142150.

Becker, H. (2001). The epistemology of qualitative research. In R. Emerson (Ed.) Contemporary field research (2 $2^{\text {nd }}$ Ed.) (317-333). Prospect Heights, IL: Waveland Press.

Blumer, H. (1969). Symbolic interactionism: Perspective and method. Englewood Cliffs, NJ: Prentice Hall

Brown, U.M. (2001). The Interracial experience: Growing up Black/White racially mixed in the United States. Westport, CT: Praeger Publishers.

Butler, J. (1990). Gender Trouble. New York: NY. Routeledge Classics.

Byrd, M. M. (2006). Family identity: Black-white interracial family health experience. Journal of family nursing, 12(1), 1-16.

Callahan, N. S. (2013, Aug 19) Mixed Kids are always so beautiful. International New York Times. Retrieved from http://parenting.blogs.nytimes.com. 
Cohn, D. (2011). Multi-race Americans and the 2010 census. Retrieved from Pew Research Social \& Demographic trends: http://www.pewsocialtrends.org Crawford, S. E., \& Alaggia, R. (2008). The best of both worlds?: Family influences on mixed race youth identity development. Qualitative Social Work, 7(81). doi: $10.1177 / 1473325007086417$

Dace, K. L., \& McPhail, M. L. (2002). Crossing the color line: From empathy to implicature in intercultural communication. In J. N. Martin, T. K. Nakayama, \& L. A. Flores (Eds.), Readings in cultural contexts (344- 350). Mountain View, CA: Mayfield.

Dacosta, K.M. (2007). Making multiracials: State, family, and market in the redrawing of the color line. Stanford, CA: Stanford University Press.

Emerson, R.M., Fretz, R, \& Shaw, L.L. (1995). Writing ethnographic fieldnotes. Chicago, IL : The University of Chicago Press.

Frabutt, J.M., Walker, A.M., \& Mackinnon, C. (2002). Racial socialization and quality of mother/child interactions in African American families. Journal of Early Adolescence, 22(2), 200-117.

Funderburg, L. (2013). Changing Faces. National Geographic. Retrieved from Nationalgeographic.com.

Glaser, B. G., \& Strauss, A. L. (1967). The discovery of grounded theory: Strategies for qualitative research. New York, NY: Aldine De Gruyter.

Goffman, E. (1959). The Presentation of Self in Everyday Life. New York, NY: Doubleday. 
Goodall, H. (2005). Narrative inheritance: A nuclear family with toxic secrets. Qualitative Inquiry, 11(4), 492-511.

Gordon, A. F. (1997). Ghostly matters: Haunting and the sociological imagination. Minneapolis, MN: University of Minnesota Press.

Herman, M. (2004). Forced to choose: Some determinants of racial identification in multiracial adolescents. Child Development, 75, 730-748.

Hitlin, S., Brown, J.S., \& Elder, G.H. (2006). Self-categorization in adolescence: Multiracial development and social pathways. Child Development.77(5), 12981308.

Ifekwunigwe, J.O. (2004). Let Blackness and Whiteness wash through: Competing discourses on bi-racialization and the compulsion of genealogical erasures. In (Ed.) Ifekqungigwe, J. O. Mixed race studies. (183-194). NY: New York. Routledge.

Hecht, M.L. (1993). 2002-a research odyssey: Toward the development of a communication theory of identity. Communication Monographs, 60(1), 76-82.

Jackson, R. L. (2006). Scripting the Black masculine body: Identity, discourse, and racial politics in popular media. NY: New York. State University of New York Press. Jimenez, T.R. (2004). Negotiating ethnic boundaries. Ethnicities, 4(1), pp. 75-97. Joseph, N. \& Hunter, C.D. (2011). Ethnic-racial socialization messages in the identity development of second-generation Haitians. Journal of Adolescent Research, 26(3), pp. 344-380. 
Joseph, N. Watson, N.N., Wang, Z., Case, A.D., Hunter, C.D. (2013). Rules of engagement: Predictors of Black Caribbean immigrants' engagement with African American culture. Cultural Diversity and Ethnic Minority Psychology, 19(4), 414423.

Jung, E. \& Hecht, M.L. (2004). Elaborating the communication theory of identity: Identity gaps and communication outcomes. Communication Quarterly, 52(3), $265-283$.

Kellas, J.K., (2005). Family ties: Communicating identity through jointly told family stories. Communication Monographs, 72(4), 365-389.

Kellas, J.K., \& Trees, A.R. (2006). Finding meaning in difficult family experiences: Sense-making and interaction processes during joint storytelling. The Journal of Family Communication, 6(1), 49-76.

Kellas, J.K.(2010). Narrating family: introduction to the special issue on narratives and storytelling in the family. Journal of Family Communication, 10, 1-6.

Langellier, K.M., \& Peterson, E.E. (2004). Storytelling in daily life: Performing narrative. Philadelphia, PA: Temple University Press.

Langellier, K.M., \& Peterson, E.E. (2006). “Somebody’s got to pick eggs": Family storytelling about work. Communication Monographs, 73(4), 468-473.

Lesane-Brown, C.L., Brown, T.N., \& Tanner-Smith, E.E. (2010). Negotiating boundaries and bonds: Frequency of young children's socialization to their ethnic/racial heritage. Journal of Cross-Cultural Psychology, 41(3), pp. 457-464.

Matza, D. (1969) Becoming Deviant. Englewood Cliffs, NJ: Prentice-Hall. 
McNay, M. (2009). Absent memory, family secrets, narrative inheritance. Qualitative Inquiry, 15(7), 1178-1188.

Milan, S, \& Keiley, M. K. (2000). Biracial youth and families in therapy: Issues and interventions. Journal of Marital and Family Therapy. 26(3), 305-315.

Mishler, E.G. (2006). Narrative and identity: The double arrow of time. In (Eds.) De Fina, A, Schiffrin, D, \& Bamberg, M. Discourse and Identity: Studies in Interactional Sociololinguistics. 23, 30-47.

Omi, M. \& Winant, H. (1993). Racial formation in the United States from the 1960s to the 1990s (2nd ed.). New York, NY: Routledge.

Perez, A. D., \& Hirschman, C. (2009). The changing racial and ethnic composition of the US population: Emerging American identities. Population and Development Review, 35(1), 1-51.

Peterson, E.E., \& Langellier, K. M. (2006) The performance turn in narrative studies. Narrative Inquiry, 16(1), 173-180.

Root, M.P.P. (1992). Racially mixed people in America. Newbury Park, CA: Sage Publications.

Root, M.P.P. (1996). The Multiracial child resource book. Seattle, WA: Mavin Foundation.

Rosenblatt, P.C. \& Wallace, B. R (2005). Narratives of grieving African-Americans about racism in the lives of deceased family members. Death Studies. 29, 217-235

Senna, D. (2004). The Mulatto Millennium. In (Ed.) Ifekqungigwe, J. O. Mixed Race Studies. (205-213). NY: New York. Routledge. 
Smith, B. \& Sparkes, A.C. (2008). Contrasting perspectives on narrating selves and identities: an invitation to dialogue. Qualitative Research, 8(1), 5-35.

Soliz, J., Thorson, A.R., \& Rittenour, C.E. (2009). Communicative Correlates of Satisfaction, Family Identity, and Group Salience in Multiracial/Ethnic Families. Journal of Marriage and Family, 71, 819-132.

Somers, M. R. (1994). The narrative constitution of identity: A relational and network approach. Theory and Society 23, 605-649.

Strauss, A. \& Corbin, J. (1998). Basics of qualitative research: Techniques and procedures for developing grounded theory. Thousand Oaks, CA: Sage Publications.

Taylor, S. \& Littleton, K. (2006). Biographies in talk: A narrative-discursive research approach. Qualitative Sociology Review, 2(1), 22-38.

Thomas, A.J., Speight, S.L., \& Witherspoon, K.M. (2010). Racial socialization, racial identity, and race-related stress of African American parents. The Family Journal, 18(4), pp. 407-412.

Thompson, B., Kellas, J.K., Soliz, J., Thompson, J., Epp, A., \& Schrodt, P. (2009).

Family legacies: constructing individual and family identity through intergenerational storytelling. Narrative Inquiry, 19(1), 106-134.

Warren. J. T. (2003). Performing purity: Whiteness, pedagogy, and the reconstruction of power. New York, NY: Peter Lang Publishing.

Wengraf, T. (2001). Qualitative research interviewing: biographic narrative and semistructured methods. UK, London: Sage Publications Inc. 
Znaniecki, F. (1934). The Method of Sociology. New York, NY: Farrar and Rinehart. 


\section{Appendix A - Introductory Script}

Thank you for choosing to participate in this study. During the interview, I'm going to ask you to talk about your family and your racial background. If you are uncomfortable at any point during the interview you can skip the question or you can stop. I'm going to ask you to give me a code name that you would like to go by, and I'm going to ask you what it is when I turn on the audio recorder. Ok, are you ready to begin? 
Appendix B - Interview Questions

1. How do you identify yourself?

Follow up: Have you always identified yourself as you do presently? Do you remember when you started to?

Do you have any thoughts as to why?

When you are asked about race or ethnicity how do you respond?

2. What do other members of your family identify as?

Follow up: Have they ever said anything about why that is? Do you have siblings? Do they respond similarly to you?

3. What was it like to grow up in a mixed race family?

Follow up: Does your extended family have similar experiences to your family?

4. Tell me about your family. How did your family talk about your heritage?

Follow up: How did your family talk about older generations often? Was race or racial issues talked about ever? What about culture/ethnicity?

5. Do you have any family traditions?

Follow up: When did they start? Do you know why? How do you feel a part of them?

6. What were family gatherings like? Do you have a memory of a family gathering? Follow up: Do you have other forms of family gatherings? When? Why?

Did you have family dinners? What foods did you grow up eating? Why?

7. Do you know your grandparents? What are they like?

8. What has helped you make the most sense of your racial identity?

9. Are there any particular conversations about heritage or race that you remember in your family?

10. Do you think the stories you have heard from your family influence your own identity?

11. Are there ever instances when you relate to things your parents have said about their own race?

12. Do your parents ever talk about being a multiracial family?

13. Was race something that was discussed your family? In what way? 
14. Do you know did your parents met? Can you tell me a little bit more about that? What are they like?

15. How did your parents talk about family race? 


\section{Appendix C - Informed Consent}

Dear participant,

Informed consent is a process that lets participants know their rights and provides information that helps participants to decide whether they wish to volunteer for a research study. It helps you as a participant understand what the study is about and what will happen during the course of the study.

After all your questions about the study have been answered, you will be asked to sign the informed consent form. The main researcher, Mariko Thomas, will also be asked to sign the informed consent form. You will be given a copy of the signed consent form to keep.

If you have questions at any time during the research study, you should feel free to ask them and should expect to be given answers that you completely understand.

\section{Why is this study being done?}

You are invited to participate in a research study conducted by graduate student Mariko Thomas from Portland State University, Department of Communication. The researcher hopes to learn more about communication behaviors regarding family and race. The study is being conducted in partial fulfillment of the requirements for a master's degree in Communication Studies, and is under the supervision of Dr. David Ritchie, primary investigator and faculty member in the PSU Department of Communication.

\section{What are the requirements for participation?}

Participants have shown an interest in participating, are adults (i.e., at least 18 years old), and identify as more than one race.

\section{What will I be asked to do if I take part in this research study?}

If you decide to participate, you will be asked to engage in an interview with the researcher that will most likely take between 45-90 minutes. The interview will be audio recorded in the Communication Research Collaboratory at PSU in the Department of Communication, or at a quiet and private location of your choice. The interview will be about family and race.

\section{What are any risks or benefits?}

While participating in this study, it is possible that you may experience mild discomfort at being audio recorded, but after a few minutes, research shows that this 
diminishes quickly, and people become acclimated and comfortable. In addition, there is an extremely minuscule risk of a breach of confidentiality if the researcher was not careful with the data. However, because I am the primary researcher, all measures will be taken to avoid this. As a thank you will receive a gift card, and the knowledge that this study may help to increase the knowledge of what we know about communication. Lastly, if you chose a location for the interview that is not the communication research collaboratory, there may be the risk of being overheard or interrupted depending on the location picked.

\section{How will information about me be kept private or confidential?}

Any information that is obtained in connection with this study and that can be linked to you or identify you will be kept confidential. This information will be kept confidential by allowing you to pick a code name for yourself that will be used during transcription, so that neither your name nor any identifying information will appear in the final research document. Further, the transcript and video recording will be protected by being stored on a password protected computer and an online data storage system.

The Department of Communication plans to license potentially edited versions of the data - including audio recordings and transcripts of conversations, which may include explanatory notes made by the researcher - and make it available, for a fee, to other researchers for research purposes. Licensed data will be edited such that, on both audio recordings and transcripts, the following personally identifying information will be omitted such as: Participants' full name, national identification number, IP address(es), vehicle registration plate number, driver's license number, credit card number(s), and digital identities and passwords. Portland State University will oversee this licensing process, including legal and safeguarding processes.

Additionally, the PSU Human Subjects Research Review Committee may have access to the data because the researcher is a mandatory reporter under Oregon law, and any information about abuse to minors or elders or the intention to harm self or others must be reported to the authorities. Therefore, all data will be held confidential as permitted by law.

\section{What are my rights if I decide to take part in this research study?}

You have the right to ask questions about any part of the study at any time. You should not sign the informed consent form unless you have had a chance to ask questions and have been given answers to all of your questions.

\section{What will happen if I do not wish to take part in the study after all, or if I later}

\section{decide not to stay in the study?}

If you do choose to take part in the study, it is voluntary. You may choose not to take part in the study, or pull out of the study at any time during the study. After your 
participation is complete, you may contact the main researcher and request to review your data. After review, you may elect to have your data erased. If you do not participate, pull out of the study during the study, or subsequently review your data and decide to have it erased, your relationship with the study researcher will not change, and you may do so without penalty and without loss of benefits to which you are otherwise entitled.

\section{Who can I call if I have any questions?}

If you have any questions or concerns about your participation in this study you can contact researcher Mariko Thomas at mariko2@pdx.edu or 541-399-0950; or Dr. David Ritchie, primary investigator and faculty in the Department of Communication at 503-725-5384, or cgrd@pdx.edu. If you have concerns about your rights as a research subject, please contact PSU Office of Research Integrity, 1600 SW 4th Ave., Market Center Building, Ste. 620, Portland, OR 97207; phone (503) 725-2227 or 1 (877) 4804400 .

\section{If I sign, what does it mean?}

- You have read and understand all of the preceding information.

- You are willing to participate in the study's audio-recorded interview with the researcher.

- You understand the participation is voluntary and that you can back out at any time.

- You understand that and agree that audiotapes, and transcripts of you, may be provided by Portland State University for a fee to other researchers or research groups for research purposes.

Your signature indicates that you have read and understand the above information and agree to take part in this study. Please understand that you may withdraw your consent at any time without penalty, and that, by signing, you are not waiving any legal claims, rights or remedies. The researcher will provide you with a copy of this form for your own records.

Participant Signature

Print name 
To the best of my ability, I have explained and discussed the full contents of the study, including all of the information contained in this consent form. All questions of the research participant have been accurately answered.

Researcher Signature 


\section{Appendix D - IRB Approval}

Date: April 18, 2014

To: $\quad$ Lee Shaker, Benjamin Smith

From: Karen Cellarius, HSRRC Chair

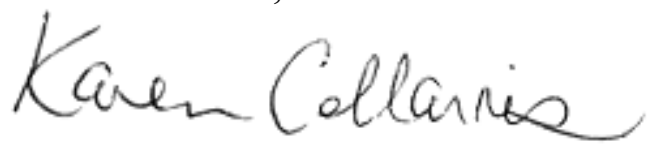

Re: HSRRC approval for your project titled, "The stories we are told" HSRRC Proposal \# 132985

Approval-Expiration: 2/10/2014-2/9/2015

\section{Notice of IRB Review and Approval-Amendment}

\section{Expedited Review as per Title 45 CFR Part 46.110, 63 FR 60366, \#}

The amendment submitted on 3/6//14 for the project identified above has been reviewed and approved by the Portland State University Institutional Review Board (IRB) and the Office of Research Integrity using an expedited review procedure. This is a minimal risk study. This approval is based on the assumption that the materials, including changes/clarifications that you submitted to the IRB contain a complete and accurate description of all the ways in which human subjects are involved in your research.

This approval is given with the following standard conditions:

1. You are approved to conduct this research only during the period of approval cited below;

2. You will conduct the research according to the plans and protocol submitted (approved copy enclosed);

3. You will immediately inform the Office of Research Integrity of any injuries or adverse research events involving subjects;

4. You will immediately request approval from the IRB of any proposed changes in your research, and you will not initiate any changes until they have been reviewed and approved by the IRB;

5. You will only use the approved informed consent document(s) (enclosed);

6. You will give each research subject a copy of the informed consent document;

7. If your research is anticipated to continue beyond the IRB approval dates, you must submit a Continuing Review Request to the IRB approximately 60 days prior to the IRB approval expiration date. Without continuing approval the Protocol will automatically expire on $2 / 9 / 2015$. 
Portland State University and the Office of Research Compliance appreciate your efforts to conduct research in compliance with PSU Policy and the Federal regulations that have been established to ensure the protection of human subjects in research. Thank you for your cooperation with the IRB process.

If you have questions or concerns, please contact the Office of Research Integrity at 503725-2227. 